\title{
ARQUEOLOGÍA EN EL PROMONTORIUM IUNONIS. UNA MIRADA DIACRÓNICA A LA OCUPACIÓN HUMANA DEL CABO DE TRAFALGAR (BARBATE, CÁDIZ)
}

\section{ARCHAEOLOGY AT THE PROMONTORIUM IUNONIS. A DIACHRONIC VIEW AT THE HUMAN SETTLEMENT OF TRAFALGAR CAPE (BARBATE, CÁDIZ)}

\section{José Juan DÍAZ ${ }^{1 *}$, Darío BERNAL-CASASOLA ${ }^{1 * *}$, Leandro FANTUZZI ${ }^{2 * * *}$, José Luis PORTILLO SOTELO $^{1 * * * *}$, Rafael JIMÉNEZ-CAMINO ${ }^{3 * * * * *}$ y José Á. EXPÓSITO ${ }^{1 * * * * * *}$}

${ }^{1}$ Dpto. de Historia, Geografía y Filosofía, Universidad de Cádiz, Avda. Dr. Gómez Ulla no 1, 11001, Cádiz

${ }^{2}$ Departament d'Història i Arqueologia, Universitat de Barcelona, c/ Montalegre no 6, 08001, Barcelona

${ }^{3}$ Departamento de Arqueología, Ayuntamiento de Algeciras, Paseo de la Conferencia no 17 (local), 11207, Algeciras

* Correo electrónico: josejuan.diaz@uca.es

** Correo electrónico: dario.bernal@uca.es

*** Correo electrónico: Ifantuzzi@ub.edu

**** Correo electrónico: joseluis.portillo@uca.es

***** Correo electrónico: cultura.arqueologia@algeciras.es

****** Correo electrónico: joseangel.exposito@uca.es

Resumen: En este trabajo se realiza una valorización diacrónica de las evidencias arqueológicas existentes en el cabo de Trafalgar desde una doble vertiente. En primer lugar, se realiza un recorrido historiográfico por los principales hitos de la investigación mientras que en segundo lugar se enumeran cada una de las fases de ocupación documentadas, caracterizando las distintas estructuras asociadas a éstas; algunas de las cuales han sido diagnosticadas o han podido ser reevaluadas gracias a los trabajos de campo desarrollados en el marco del proyecto Arqueostra (2021).

Palabras Clave: Cabo de Trafalgar, Historiografía, ocupación humana, Paisaje Cultural Marítimo, evidencias arqueológicas.

Abstract: In this paper, we value diachronically the archaeological pieces of evidence at Trafalgar Cape from a double perspective. In the first place, we present a historiographic view for the main milestones of the research. Second, we have listed each of the occupation phases that we have documented, characterizing the different structures associated with them. Some archaeological evidences have been diagnosed or have been reassessed thanks to the field work carried out within the development framework of the Arqueostra project (2021).

Keywords: Trafalgar Cape, Historiography, human settlement, Maritime Cultural heritage, Archaeological evidences.

Sumario: 1. Introducción. 2. Balance historiográfico. 3. Las fases de ocupación humana en el cabo de Trafalgar. 3.1 Área de dispersión de materiales y tumba prehistórica. 3.2 La villa maritima julio-claudia. 3.3 El balneum y el posible vicus haliéutico de la playa de Caños de Meca - Varadero. 3.4 La zona de canteras. 3.5 La necrópolis ¿altomedieval? 3.6 La torre para la defensa de las almadrabas en época moderna. 3.7 El faro del s. XIX. 4. Arqueostra y el cabo de Trafalgar: perspectivas de futuro. 5. Bibliografía. 


\section{Introducción}

Uno de los yacimientos objeto de estudio dentro del proyecto de investigación Arqueostra ${ }^{1}$ está siendo el del cabo de Trafalgar, al emplazarse en este lugar el que, hasta el momento, es el único ejemplo de piscina de acuicultura documentada en la Baetica romana (Bernal-Casasola et al., 2011). Los trabajos se planificaron para ejecutar una única campaña de excavación en el invierno de 2021, si bien los esperanzadores resultados obtenidos provocaron que se decidiese llevar a cabo una segunda campaña y se haya planificado continuar los estudios hasta mediados del año 2022 con nuevas investigaciones a ejecutar sobre el terreno.

Entre las primeras actuaciones a desarrollar estaba la de realizar un estado de la cuestión desde el punto de vista historiográfico sobre los estudios realizados en el lugar hasta ese momento. De igual forma, se trabajó sobre el terreno para individualizar y caracterizar cada una de las fases de ocupación de las que se tenían evidencias materiales previas, intentando así mostrar un análisis en clave diacrónica sobre la importancia del poblamiento humano en cabo de Trafalgar, cuyos resultados se muestran, sintéticamente, en las siguientes páginas.

\section{Balance historiográfico}

Trafalgar, además de su componente arqueológico, es uno de los espacios naturales de mayor trascendencia en la costa gaditana (Figura 1a), de ahí que sobre este ámbito se hayan desarrollado diversas políticas medioambientales de protección. Así, el promontorio junto al doble tómbolo de arena que lo une al continente y los fondos marinos que lo rodean fue declarado monumento natural en el año 2001, bajo el nombre de "Tómbolo de Trafalgar", integrándose en la Red de Espacios Naturales Protegidos de Andalucía (RENPA). Asimismo, en 2006, el cabo de Trafalgar y su entorno terrestre inmediato fueron reconocidos como Lugar de Importancia Comunitaria (LIC) de la región biogeográfica mediterránea. Además, en 2018 se estableció la Zona de Especial Conservación (ZEC) Punta de Trafalgar, quedando también integrado a partir de 2021 dentro del Parque Natural de la Breña y Marismas del Barbate. El promontorio debió formarse hace unos $107000 \pm 2000$ años (Zazo et al., 1999), estando configurado por conglomera- dos conchíferos y areniscas sobre los que se ha ido desarrollando una duna fósil con alturas máximas de $20 \mathrm{msnm}$ (Gracia et al., 2011), lo que provoca que, además de estar separado del resto de la línea de costa unos cientos de metros lo configura como un referente náutico de primer orden para la navegación. En el doble tómbolo que lo une a ese borde marítimo - terrestre, se desarrollan actualmente sendas playas con dinámicas litorales muy diferenciadas, con un sistema dunar consolidado $\mathrm{y}$ un espacio de lagoon al interior rellenado también por dunas de origen eólico y limos (Cabero et al., 2009). En este contexto, y aunque nuestro proyecto está dirigido principalmente hacia un análisis de la ocupación humana de este territorio, su carácter interdisciplinar nos ha llevado a emprender trabajos de carácter geoarqueológico en la zona junto a los investigadores de la Université de Strasbourg, F. Salomon y G. Rixhon, de los cuales esperamos poder ofrecer resultados en un futuro próximo que nos permitan resolver algunas cuestiones aún hoy abiertas, entre las que podríamos destacar las de conocer si el promontorio fue isla en algún instante o la caracterización y cronología de la formación de los diversos lagoons que caracterizan la zona.

Y es que las particularidades de Trafalgar han hecho de este yacimiento uno de los referentes del estudio geológico de la costa gaditana. En este sentido, además de su constitución y dinámica geomorfológica, este espacio ha sido objeto de análisis por las evidencias materiales que allí se tienen registradas de los efectos de los diferentes eventos de alta energía acaecidos en nuestro litoral (veintiuno conocidos desde el "supuesto" del año 218 a.C. hasta el presente según J.M. Martínez, 2005). Entre ellos, del que más datos se tiene es el del terremoto y posterior tsunami de 1755 . En este caso, la presencia sobre la rasa marina de unos ochenta bloques de roca de notables dimensiones (entre 2 y $7 \mathrm{~m}$ de longitud y más de un 1 $\mathrm{m}$ de grosor) y peso (algunos de $10 \mathrm{Tn}$ ) solo puede justificarse por la erosión en el fondo marino y traslado de esos clastos por un evento de esa naturaleza (Figura 1b); lo que unido a la localización de algunos de ellos sobre los restos de unas canteras de posible cronología medieval, ha favorecido su relación con el citado maremoto (Scheffers y Kelletat, 2003; Gracia et al., 2006; con controversia en Cabero et al., 2009). Además, en diferentes zonas del doble tómbolo hay otra serie de registros de clastos y bloques de diferente naturaleza y di- 

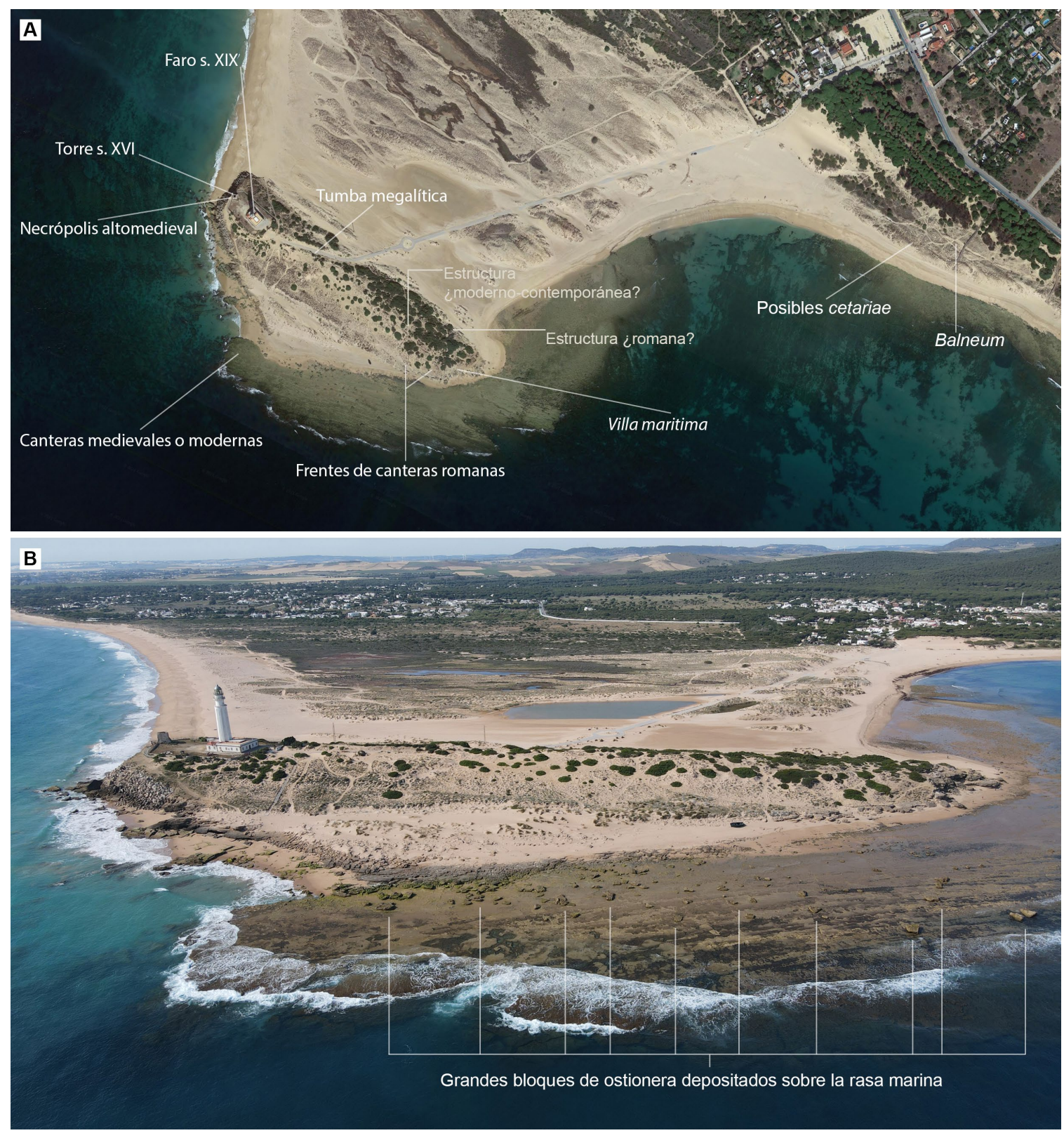

Figura 1. Vista aérea del cabo de Trafalgar en la que se aprecia el entorno natural en el que se emplazan los principales testimonios arqueológicos conocidos (a); fotografía aérea de la rasa marina en la que se observa la superposición de grandes clastos procedentes del fondo marino que evidenciarían su disposición en ese lugar como consecuencia de eventos de alta energía (b). (Fuente: Proyecto Arqueostra).

mensiones que debieron transportarse y depositarse en esos espacios por este u otros eventos de alta energía.

Por su parte, desde el punto de vista histórico, ya en las fuentes clásicas el lugar aparece referenciado como el promontorium Iunonis. Autores como Ptolomeo (Geog. II 4, 5), Plinio (Nat. III, 7), Pomponio Mela (De Chorographia II, 96), Marciano (Peripl. 2.3, 2.9) o Avieno (Ora Mar. V, 322) hablan tanto del cabo como elemento de referencia náutica como de un templo dedicado a la diosa Juno - Hera (Pérez, 1989); si bien el espacio pudo estar sacralizado desde época fenicio - púnica, dedicado al culto a Astarté (Marín, 2010). Evidencias tangibles de estructuras de carácter cultual no se han documentado hasta el momento; algo que ya puso de manifiesto G. Bonsor hace algo más de cien años (Bonsor, 1918: 142), a pesar de que en algunas publicaciones se menciona la posibilidad de que las estructuras arqueológicas existentes en la zona sureste del tómbolo -descritas por I. Pérez y que realmente deben vincularse con la villa maritima romana- pudieran asociarse con ese espacio sacro (Marín, 2010: 495-496, nota 15). Aunque no 
recogido en las fuentes clásicas, la zona también fue conocida como Beca, si bien este topónimo a pesar de su origen prerromano comenzó a aparecer en época islámica para denominar a la ciudad que en el entorno de la actual Caños de Meca se erigió (problemática en Abellán, 1985-1986: 361364). Por su parte, el topónimo actual de Trafalgar tiene un origen árabe (al-)tar(a)f al-agarr = cabo blanco o cabo brillante; probablemente vinculado al color que emanaban las arenas de las dunas que coronaban el promontorio.

En cuanto a los restos de época romana, éstos se conocen desde hace mucho tiempo, pues de ellos tenemos referencias en Ceán Bermúdez (1832), o incluso antes, en 1771, por T. James (referencia en Ponsich, 1988: 203-206). Sin embargo, fue hace solo poco más de cuarenta años cuando F. Amores vino a dar luz sobre el conocimiento de la fase romana del yacimiento, caracterizando, gracias a su visita y prospección del lugar, dos áreas o núcleos por donde se extendían en superficie las evidencias materiales de dicha ocupación romana (Amores, 1978). El primer núcleo se emplazó en el extremo suroriental del promontorio y en él este investigador individualizó una serie de estancias distribuidas en terrazas de entre las cuales destacaba la presencia de un aljibe recubierto en su interior por opus signinum y dos balsas, también revestidas de ese tipo de hormigón hidráulico que le sirvió para vincularlas con una cetaria. Junto a estas estructuras se sucedían a lo largo del perfil del acantilado restos de muros y pavimentaciones correspondientes a diferentes estancias, mencionando el autor la existencia hacia el oeste de un área de cantera. Por su parte, el llamado núcleo 2 se distanciaba del primero unos centenares de metros ubicándose en la playa de Varadero o "Marisucia”, cercana a Los Caños de Meca. Allí, en la zona interdunar, se alzaba un inmueble de notable envergadura, del cual hemos tenido la oportunidad recientemente de acceder a una serie de fotografías que evidencian la realización de actuaciones incontroladas de excavación sin metodología arqueológica desarrolladas unos años antes (Figura 2a). En su estudio, Amores pudo identificar dos estancias, así como otra serie de muros que evidenciaban la continuidad del inmueble por los alrededores (Figura 2b). La existencia de una serie de oquedades en la cara interna de algunas de las paredes del edificio favoreció la interpretación del espacio como un secadero de pescado al vincular esos huecos con los puntos de anclaje de tirantes donde colgar los pescados. Por último, de este trabajo también debemos ensalzar la propuesta cronológica del yacimiento. En este caso, la ausencia de barnices negros y cerámica fina africana, y la presencia de sigilatas altoimperiales itálicas, gálicas e hispánicas, paredes finas o barniz rojo pompeyano favoreció una datación de los contextos entre época augustea (último cuarto del s. I a.C.) y comienzos del s. II d.C. (Amores, 1978: 452).

Años más tarde, el yacimiento fue objeto de inclusión en la carta arqueológica del T.M. de Barbate (Bernabé, 1990 publicada finalmente en 2010) otorgándosele la funcionalidad de villa. En esos años de comienzos de la década de los noventa, un fuerte temporal en la zona provocó el desmonte parcial de la duna en la playa de Varadero, sacando a la luz restos constructivos de época romana, los cuales fueron objeto de una intervención arqueológica de urgencia, dirigida por M.A. Sáez. Aunque los resultados no fueron publicados ni depositados en la Delegación Provincial de Cultura de Cádiz, posteriormente algunos investigadores mencionaban la aparición de varias balsas de salazón junto a unos restos -quizás los del núcleo 2 de Amores- interpretados como un posible columbario (Lagóstena, 2001: 454)2 ${ }^{2}$. Estos datos, pero sobre todo la funcionalidad otorgada por F. Amores como fábrica salazonera de los restos emplazados en el promontorio provocó su inclusión dentro de otros estudios generales de carácter haliéutico como los de M. Ponsich (1988), R.I. Curtis (1991) o R. Etienne y F. Mayet (2002).

En esos años de finales del s. XX y comienzos del s. XXI también hay que destacar una serie de publicaciones (Romero, 1994; Sáez, 2001; Valdecantos, 1996) que versaron sobre el sistema de fortificación que desde época medieval comenzó a jalonar la costa gaditana, acercándose entonces a la torre situada en el extremo noroccidental del tómbolo. De igual forma, y en el marco de desarrollo del PGI La ocupación prehistórica de la campiña litoral y banda atlántica de Cádiz, un equipo de la Universidad de Cádiz dirigido por J. Ramos prospectó el término municipal de Barbate, y por ende el cabo de Trafalgar. En el tómbolo documentaron en las inmediaciones del yacimiento romano material lítico tanto del Paleolítico Inferior-Medio como de la Prehistoria Reciente asociado con cerámicas a mano que preludiaban una ocupación del lugar por sociedades del III-II milenio a.C. (Ramos et al., 2002, 2008). 

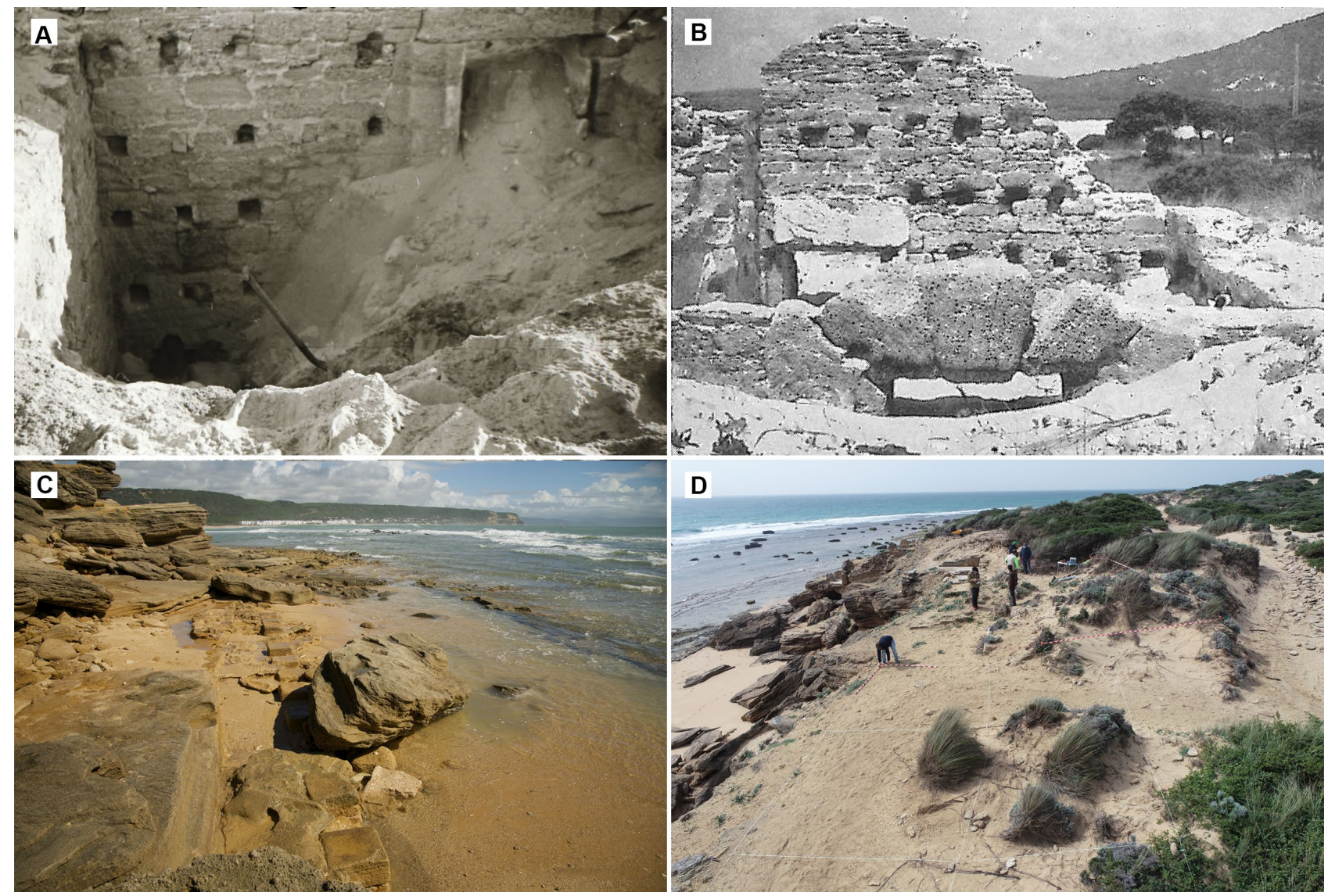

Figura 2. Detalle de los restos del balneum a principios de la década de los setenta del s. XX tomada desde el norte y en la que se aprecia la excavación realizada por furtivos (a); detalle de los restos documentados por F. Amores visto desde el sur (b); detalle del cierre septentrional del vivero sacado a la luz tras el temporal Emma

en marzo de 2018 (c); vista general de los trabajos de excavación desarrollados en 2021 durante la primera campaña en la villa maritima (d). (Fuente: a partir de fotografía sin autoría; Amores, 1978: lam. XX, c; A. Aragón y Proyecto Arqueostra).

Por su parte, la dicotomía factoría de salazones/villa para los restos romanos del promontorio se mantuvo en nuevos trabajos como los de A. Fornell (2005) que integró el yacimiento como probable villa dentro de su catálogo de asentamientos villáticos béticos. Una década más tarde D. Bernal-Casasola (2016) precisó su identificación relacionándola con el modelo de villa maritima en el último catálogo publicado sobre este tipo de asentamientos de carácter rural en la Baetica coordinado por R. Hidalgo. Ese apelativo de "marítima" no solo ha de vincularse con su franca relación con el mar circundante, sino porque el asentamiento presentaba unas características tanto edilicias como cronológicas y simbólicas propias de los ambientes itálicos donde se extendieron este tipo de haciendas. Y para ello, se valió de otra investigación que realizó este investigador junto con C. Alonso y J. Gracia unos años antes en las que publicaron los indicios de la que venía a ser la primera pisci- na de acuicultura documentada en tierras béticas (Bernal-Casasola et al., 2011), de similares características arquitectónicas y funcionales a las documentadas en el entorno del mar Tirreno (Laffon, 2001). Por último, indicar que, en ambos estudios, se manifestaba la vinculación de la villa con actividades haliéuticas, pero se dejaba en interrogación la existencia de una cetaria en el promontorio, al disociar las dos balsas conocidas hasta la fecha con las piletas canónicas donde se elaborarían salsas y salsamenta, pues las documentadas por F. Amores presentaban escalonamientos al interior que no suelen darse en las cubetas salazoneras.

Otro temporal, en este caso acaecido en el invierno de 2018, provocó la aparición de nuevo de la piscina para el engorde y cría de pescado y/o moluscos, pudiendo A. Aragón documentar gráficamente por primera vez su cierre perimetral septentrional (Figura 2c), el cual se diferenciaba del meridional y oriental ya publicados en que 
sobre el retalle en la roca se alzaban sillares de ostionera. Este mismo investigador, como técnico municipal del auntamiento de Barbate, redactó un informe unos meses más tarde tras el hallazgo casual en el extremo occidental del promontorio de restos óseos humanos en el interior de una tumba excavada en la roca, la cual se asoció en un primer momento con la necrópolis de la villa romana existente en el extremo opuesto.

Con estas premisas, tras la aprobación del proyecto Arqueostra que como hemos mencionado al comienzo de este trabajo está centrado en el estudio de los orígenes de la acuicultura en esta área geográfica del círculo del Estrecho, se decidió emprender y retomar la investigación en el cabo de Trafalgar, habiéndose realizado hasta la fecha dos campañas de excavación (Figura 2d); la primera en marzo y la segunda en mayo de 2021, a las que se le han intercalado trabajos de geoarqueología y prospecciones geofísicas de cara a nuevas intervenciones a desarrollar en un futuro inmediato entre finales del año $2021 \mathrm{y}$ el primer semestre de 2022 que posibiliten aumentar el conocimiento y favorezcan la puesta en valor tanto de los restos de la villa maritima y la cetaria anexa (Bernal-Casasola et al., 2022; Díaz et al., 2021) como de la tumba megalítica de principios del II milenio a.C. aparecida en el tómbolo; o del balneum y las posibles fábricas salazoneras emplazadas en la zona de Caños de Meca, en la playa de Varadero.

\section{Las fases de ocupación humana en el cabo de Trafalgar}

Como se ha podido vislumbrar en el apartado precedente, varios son los testimonios de la ocupación humana en el cabo de Trafalgar a lo largo del tiempo desde la Prehistoria hasta nuestros días (vide supra figura 1). En esta primera fase de actuación que hemos desarrollado, se ha realizado un esfuerzo por caracterizarlos de forma unitaria, de lo cual se exponen a continuación los resultados obtenidos, de manera sintética.

\section{1. Área de dispersión de materiales y tumba prehistórica}

Entre los objetivos desarrollados en la primera campaña de excavación a ejecutar en la villa maritima romana estaba el de delimitar su extensión. Para ello, se procedió a realizar una prospección del terreno al este del último muro visible, pudién- dose determinar que en ese extremo del yacimiento se había desmantelado por la acción antrópica reciente un gran conchero vinculado a las actividades haliéuticas de la villa (Bernal-Casasola et al., 2022). Pero, además, en superficie junto a material cerámico altoimperial y la gran cantidad de malacofauna -principalmente Phorcus lineatusque permitió definir la funcionalidad del espacio, se recuperaron algunos fragmentos de sílex y cerámicas a mano que advertían de la presencia de una fase de ocupación durante la Prehistoria Reciente. Con el objetivo de documentar con mayor precisión los restos en superficie se planteó el sondeo 3 en una superficie de $256 \mathrm{~m}^{2}$, dividido en ocho subcuadrículas de $4 \times 4 \mathrm{~m}$, anotándose en planta la georreferenciación de los hallazgos. La concentración de materiales a mano en las cuadrículas G y $\mathrm{H}$ favoreció que en esta última practicásemos una pequeña excavación que propició el hallazgo de un nivel de combustión (Figura 3a) y un área de concentración de materiales -principalmente cerámicas a mano- que posibilitaron la datación del contexto en el III-II milenio a.C. (Figura 3b). A esa primera fase de ocupación del lugar en época prehistórica habría que añadirle la localización en la parte central de la ladera norte del promontorio junto a la margen izquierda de la carretera de acceso al faro de grandes lajas de piedra. Esta serie de ortostatos de caliza, ocultados parcialmente por la duna y la vegetación (Figura 3c), pero dispuestos con cierto orden nos hizo pensar en la posibilidad de que estuviésemos ante un enterramiento, tal y como ya se había indicado en los trabajos de prospección efectuados en la zona a comienzos del s. XXI (Ramos et al., 2002). La intervención que se ha ejecutado en la segunda campaña de excavación de este proyecto ha venido a confirmar la funcionalidad funeraria de la misma y la existencia, por tanto, de un área cementerial prehistórica en el cabo de Trafalgar de notable envergadura ${ }^{3}$.

\subsection{La villa maritima julio-claudia}

Como hemos visto en el apartado precedente, la villa de Trafalgar ha sido estudiada por diferentes investigadores que han ido poco a poco dando forma al conocimiento actual de los restos (Amores, 1978; Bernal-Casasola, 2016; Bernal-Casasola et al., 2011). De igual forma, recientemente se ha publicado otro trabajo en el que se analiza de forma pormenorizada la estructuración, caracterización funcional y elementos arquitectónicos em- 


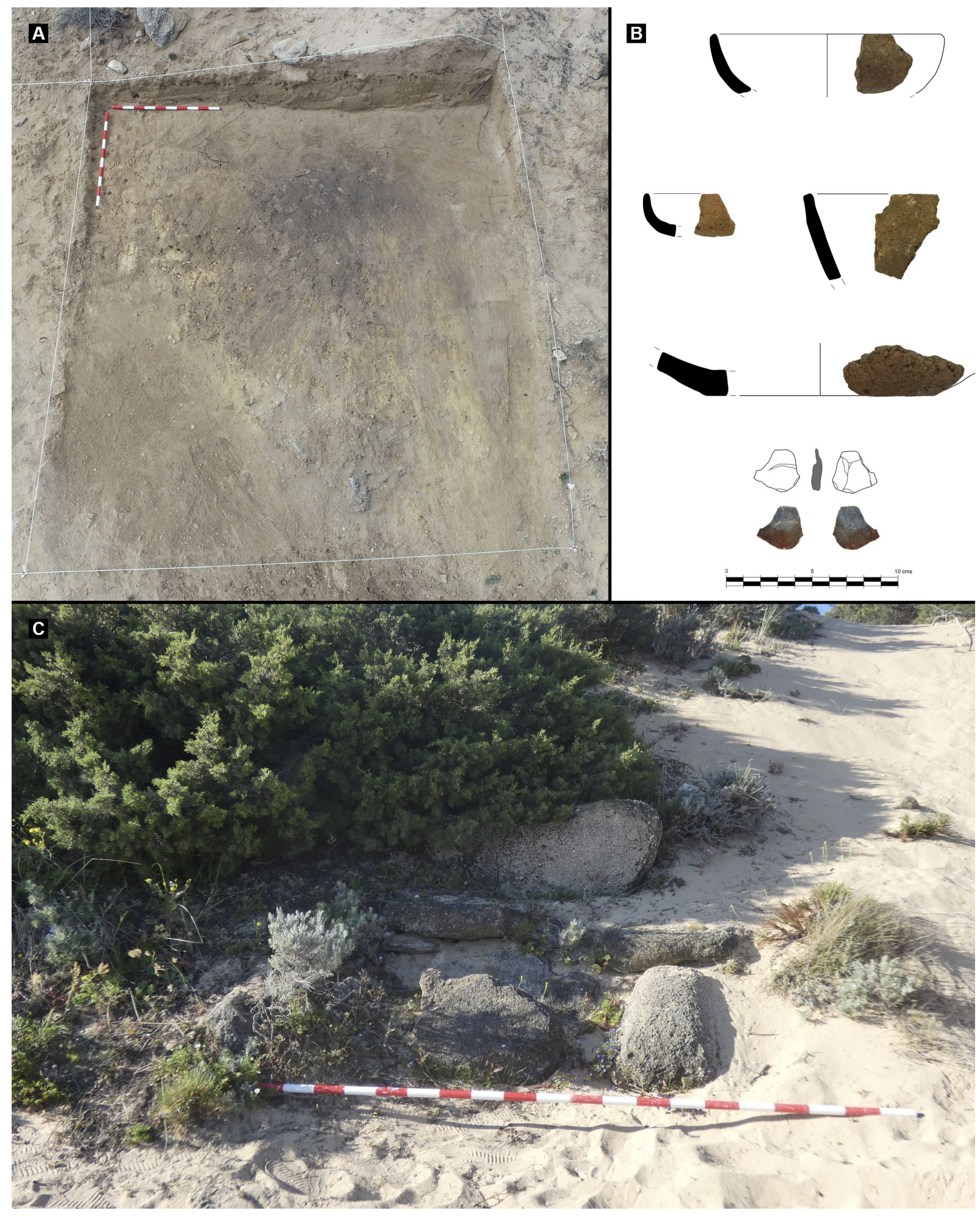

Figura 3. Detalle del corte estratigráfico practicado en el sondeo 3 con el nivel de combustión documentado (a), formas abiertas de cerámica a mano y producto lítico tallado documentado en el sondeo 3 (b); vista del estado en el que se encontraban los ortostatos de la tumba megalítica en el momento de su localización antes de su excavación (b). (Fuente: Proyecto Arqueostra). 
pleados en cada uno de los espacios en los que se ha podido dividir el inmueble, resaltando entre las cuestiones tratadas la existencia de una fábrica de salazones anexa a la pars urbana y el empleo de una rica decoración arquitectónica en esta última, con mosaicos bicromos, pintura mural en paredes y techos vinculados al III estilo pompeyano (Díaz et al., 2021). Remitimos a las lecturas de todos ellos para una mejor comprensión del edificio y su problemática, pues en estas páginas solo llevaremos a cabo una valoración e interpretación general de los hallazgos.

En esta línea, debemos mencionar cómo el edificio fue construido en el extremo suroriental del promontorio adaptándose al terreno, para lo cual se establecieron hasta cuatro terrazas si contamos como primera la plataforma rocosa sobre la que se construyó la piscina de acuicultura. La villa debió ser obra de itálicos, siguiendo los patrones establecidos en la zona tirrena entre Cosa y Paestum (Bernal-Casasola et al., 2011: 157), en las últimas décadas del s. I a.C., en un fenómeno de exportación de este modelo de hacienda a la península Ibérica que tiene su reflejo más contundente en la costa mediterránea alicantina (Olcina, 2011). El asentamiento no tuvo un dilatado desarrollo en el tiempo como suele ser habitual en este tipo de hábitat, abandonándose algunas generaciones más tarde, en época claudio-neroniana. Aún se desconocen las causas del mismo, si bien como hipótesis podríamos plantear cuestiones geomorfológicas de erosión marina del acantilado sobre el que se dispuso el inmueble; en paralelo a ello la afección de las estructuras por algún evento traumático, constatado en otros yacimientos cercanos para esas fechas (Silva y Giner-Robles, 2014) y que tendría su evidencia material en la documentación de muros y techumbres desplomadas en algunas estancias excavadas, o bien cuestiones de calado socio-político como podría ser el traslado de sus possesores -representantes de la oligarquía de la zona- a ciudades ya consolidadas (como Baelo Claudia), donde sus influencias políticas y ganancias económicas podrían ser más ostensibles.

Del inmueble se conocen diferentes espacios (Figura 4). En la zona inferior en contacto con el mar se construyó la piscina para la cría y engorde del pescado. Tenía una planta rectangular con una superficie de $168 \mathrm{~m}^{2}$ y una capacidad hídrica de algo más de $50 \mathrm{~m}^{3}$, con retalles de entrantes y salientes en las paredes y muros interiores que la convertirían en una posible piscina loculata con compartimentaciones interiores que podrían servir para no mezclar los productos piscícolas que se estuvieran criando (Bernal-Casasola et al., 2022). Además del aporte de agua dulce procedente del aljibe cercano, hacia el mar tendría dos canales de conexión que facilitarían la entrada, salida y control de este otro tipo de agua para generar un ambiente salobre tan característico de este tipo de instalaciones. Como hemos indicado, otro de los elementos funcionales que albergó el edificio fue un gran aljibe de sección troncopiramidal y de notable entidad que tenía la particularidad de haber sido excavado en la roca y contar con revestimiento de opus signinum. Su disposición centrada con respecto al resto de espacios funcionales de la villa en una amplia estancia, le otorgan cierto eje vertebrador y funcional a esta estructura hídrica pues, además de favorecer el aporte de agua dulce al vivero, con seguridad también debió usarse tanto para las necesidades cotidianas de la pars urbana como de las productivas de la cetaria anexa situadas ambas en las terrazas superiores en donde se abriría el brocal del aljibe. A pesar del elevado grado de destrucción al que se han visto afectadas las terrazas intermedias, algunas de las estancias emplazadas en dicha zona se han mantenido, aunque sea parcialmente hasta nuestros días, ofreciendo interesantes datos sobre la distribución de la villa y la funcionalidad de distintos espacios. Entre ellos mencionaremos en el extremo occidental la presencia de dos estructuras revestidas en sus paredes de opus signinum, con rebancos y suelos también con este tipo de hormigón hidráulico que se encontraban en el último momento de uso interconectadas. Entre sus funcionalidades, a determinar en un futuro, se ha propuesto su posible vinculación con cubetas para favorecer la crianza de especies piscícolas antes o después de su paso por el vivero; o de piscinas de agua fría vinculadas con un espacio termal dentro de la zona residencial de la villa. Finalmente, de la terraza superior destacamos por un lado la presencia de una fábrica de salazón con varias piletas dispuestas en batería (Bernal-Casasola et al., 2022). De igual forma, hacia el oeste se abrían una serie de habitaciones en las que se emplearon como elementos arquitectónicos placas de mármol, capiteles con hojas de acanto para rematar pilastras o dovelas que nos hablan de estructuras arcadas entre otros elementos. Todo ello, junto a los restos aparecidos en los niveles de amortización de las piletas salazoneras -cerca de un millar de teselas blancas y negras de 


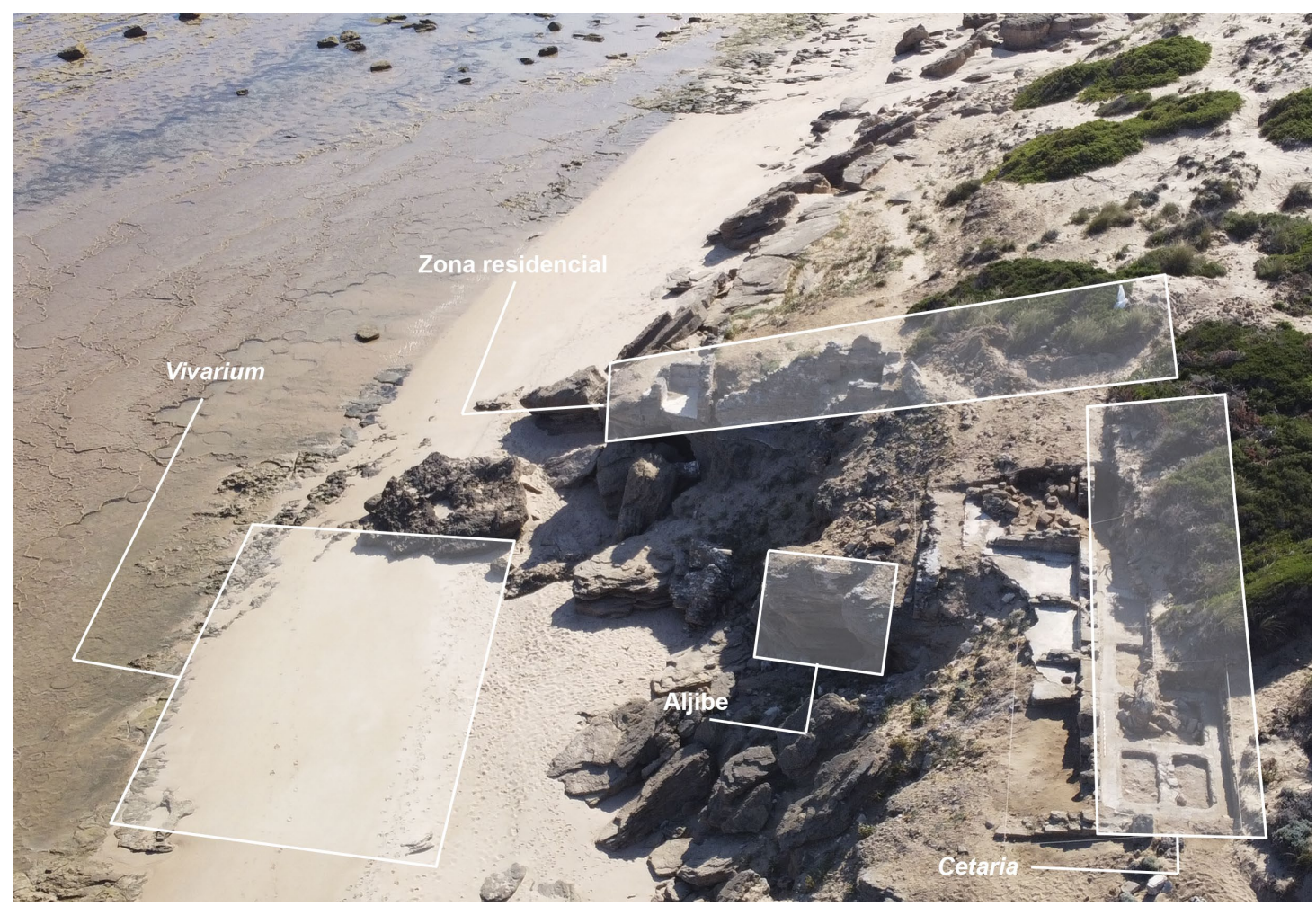

Figura 4. Vista aérea de los restos arqueológicos de la villa marítima con indicación de los principales espacios documentados. (Fuente: Proyecto Arqueostra).

un pavimento musivario desmantelado y numerosos fragmentos de pintura mural pertenecientes tanto a paredes como a techos- (Díaz et al., 2021) nos hablan del cuidado programa arquitectónico empleado en busca de la escenografía del paisaje y del otium de esos colonos itálicos que debieron erigir el edificio 4 .

\subsection{El balneum y el posible vicus haliéutico de la playa de Caños de Meca - Varadero}

Resulta sorprendente la pérdida de la memoria patrimonial que había afectado a los restos arqueológicos ubicados en la playa de Caños de Meca - Varadero. Es cierto que la dinámica litoral de la zona, con la presencia de dunas móviles, así como la repoblación de pinares ha favorecido la transformación paisajística del entorno desde la publicación de las estructuras de F. Amores (vide supra figura $2 \mathrm{~b}$ ) hasta nuestros días. Como ejemplo de ello tenemos la práctica cubrición de las estructuras que a finales de la década de los setenta del pasado s. XX presentaban un alzado máximo de 2,40 m de altura y diferentes muros que permitían diferenciar varias estancias, con respecto a lo que en 2021 de ella se vislumbraban, con un único muro del que se apreciaba apenas unos $50 \mathrm{~cm}$ de alzado correspondiente a las hiladas superiores (Figura 5a). Pero es que, además, también se había perdido el recuerdo a su existencia por parte de la administración y la propia sociedad. Así, de su ubicación o grado de conservación no se tenían datos en las instituciones públicas competentes, ni en la Delegación Provincial de Cultura de Cádiz ni en el Parque Natural de la Breña y Marismas del Barbate en cuyos límites se encuentra integrado ${ }^{5}$. Y como decimos, había prácticamente desaparecido del imaginario colectivo como evidencia el asombro y enorme impacto mediático y social que ha causado su redescubrimiento en la primavera de $2021^{6}$.

Las primeras actuaciones desarrolladas sobre estas estructuras, aún inéditas ${ }^{7}$, han permitido clarificar la funcionalidad del inmueble dado a conocer por F. Amores en el llamado núcleo 2, desvinculándolo de un secadero de productos piscícolas para asociarlo con un espacio termal de carácter rural. En este caso, las oquedades que presentaban al interior de los muros algunas estancias han sido reinterpretadas como los huecos necesarios para la inserción de las clavijas de sujeción de los muros tabiqueros de las dobles paredes -concamerationes- que albergaron las salas calefactadas. Asimismo, la confirmación del uso termal deriva 
del hallazgo del sistema de sustentación del hipocaustum de una de las salas. Además, del balneum se han vuelto a documentar diversos muros de notable entidad que presentan ventanas y umbrales por los que los usuarios debieron ir accediendo al programa arquitectónico típico de este tipo de instalaciones con la trilogía frigidarium, tepidarium y caldarium y salas anexas de distribución y trabajo (Figura 5b). En cuanto a su cronología todo parece indicar que fue construido en época altoimperial -probablemente en el s. I d.C.- manteniéndose en funcionamiento hasta el s. V d.C. Esta cronología, disonante con la propuesta para la villa maritima, nos puede estar hablando de un posible traslado de la actividad haliéutica desde el promontorio hacia la playa, y es que según noticias orales bajo las dunas que separan el balneum de la zona intermareal se conservan restos de piletas que bien pudieron haber formado parte de un edificio salazonero. Aquí hay que volver a incidir en el temporal acaecido al comienzo de la década de los noventa del pasado s. XX que desmontó las dunas y sacó a la luz una serie de estructuras murarias. En la actualidad, a algo más de $100 \mathrm{~m}$ aproximadamente al suroeste del balneum se tiene atestiguado -en superficie en un pequeño calvero existente en el sistema dunar- los restos de una estructura muraria realizada con opus vittatum de calizas grises, que bien podría vincularse con uno de los muros de cierre de esa posible fábrica (Figura 5c); la cual esperamos en un futuro poder sacar a la luz y obtener así mayor información sobre la misma.

\subsection{La zona de canteras}

La labor de extracción de piedra en el tómbolo de Trafalgar tiene evidencias físicas en dos espacios claramente diferenciados tanto por su ubicación como por la tipología de los frentes y cortes efectuados (Figura 6a).

El primero de ellos se documenta en la ladera meridional del promontorio en su parte central donde, a su vez, se distinguen dos frentes de cantera. Ambos se configuraron como explotaciones a cielo abierto con cortes angulares sobre la biocalcarenita conchífera para la extracción de sillares. El más oriental se sitúa a escasamente algo más de cincuenta metros del extremo occidental de la villa maritima, extendiéndose por una superficie de unos $17 \mathrm{~m}$ con frentes de hasta $4 \mathrm{~m}$ en sentido N-S (dirección costa - interior del tómbolo) (Figura 6b), si bien es probable que éstos pudiesen ser de mayor amplitud y actualmente estar recubiertos de arenas de playa. De igual forma, sólo es visible una altura de corte, pero en superficie encontramos arenas y no la roca natural, por lo que tampoco es descartable la existencia de otras hileras de extracción inferiores. Se observan varios frentes escuadrados con retalles rectos de tamaño variable (entre 80 y $120 \mathrm{~cm}$ ), que podrían evidenciar el volumen que alcanzaron los sillares extraídos; y retranqueos de unos 10-15 cm entre ellos. Los negativos de esos frentes están recortados en vertical; sin embargo, en los retranqueos el negativo en la roca ostionera se esculpió en bisel con el objetivo de hacer palanca y extraer los sillares. Por último, mencionar cómo en algunos de esos frentes de extracción se conservan aún varios bloques a medio extraer, lo que es una prueba irrefutable de la funcionalidad de este espacio como zona de extracción de material constructivo.

Por su parte, el segundo se encontraría a otros cincuenta metros al oeste, siendo de mayor envergadura (Figura 6c). En dimensiones alcanza unos $26 \mathrm{~m}$ sentido E-O, por unos $10 \mathrm{~m}$ sentido $\mathrm{S}-\mathrm{N}$, si bien por la cubrición dunar el frente septentrional no se encuentra visible actualmente en toda su extensión. De esos más de veinticinco metros de frente de extracción, los doce más occidentales son los que mayor información nos aportan, pues en ellos se atestiguan hasta tres niveles de extracción con varios paños longitudinales -algunos de caso $9 \mathrm{~m}$ - entre los que se intercalan algunos retranqueos con cortes biselados para favorecer la extracción de los sillares. La altura de los tres niveles de extracción es similar entre los 60 y $70 \mathrm{~cm}$, lo que nos daría una idea de la altura de los bloques exhumados en esta zona de cantería.

Algunos de los sillares que se quedaron en ambas áreas sin terminar de extraer presentan unas medidas $(60 \times 40 \times 25,46 \times 25 \times 25$ o $60 \times 60 \times 40 \mathrm{~cm})$ que son idénticas a algunos de los documentados en los muros que forman parte de la villa maritima. Además, la técnica empleada en cuanto a su modo de extracción es de similar factura a algunos frentes de sillares y otros elementos arquitectónicos en las canteras romanas de Punta Camarinal (Domínguez-Bella, 2016: 100, fig. 10A), lo que vendría a reforzar la hipótesis de su vinculación con la fase de ocupación romana del tómbolo.

El segundo de los espacios se sitúa de forma amplia en la rasa marina, advirtiéndose zonas de extracción tanto en las cercanías de la villa -a escasos metros de la piscina de acuicultura- como 

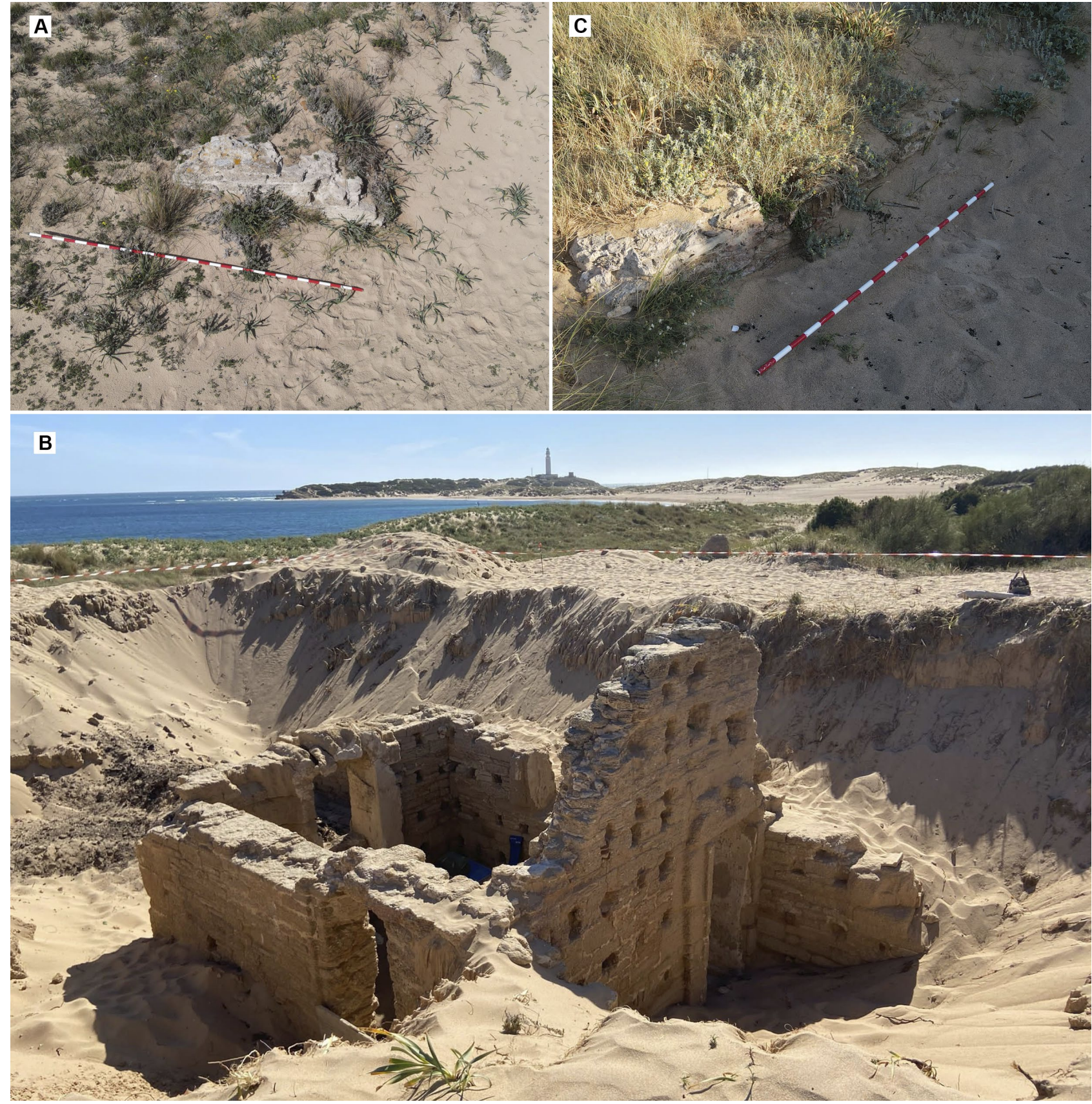

Figura 5. Detalle del único muro perteneciente al balneum visible a comienzos de 2021 (a); vista aérea de los restos exhumados del edificio termal en la primavera de 2021 (b); detalle de los restos de una estructura muraria que se vislumbra parcialmente en el espacio dunar junto a la zona intermareal de la playa de Caños de Meca - Varadero (c). (Fuente: Proyecto Arqueostra). 
DÍAZ, José Juan, BERNAL-CASASOLA, Darío, FANTUZZI, Leandro, PORTILLO SOTELO, José Luis, JIMÉNEZ-CAMINO, Rafael y EXPÓSITO, José Á.

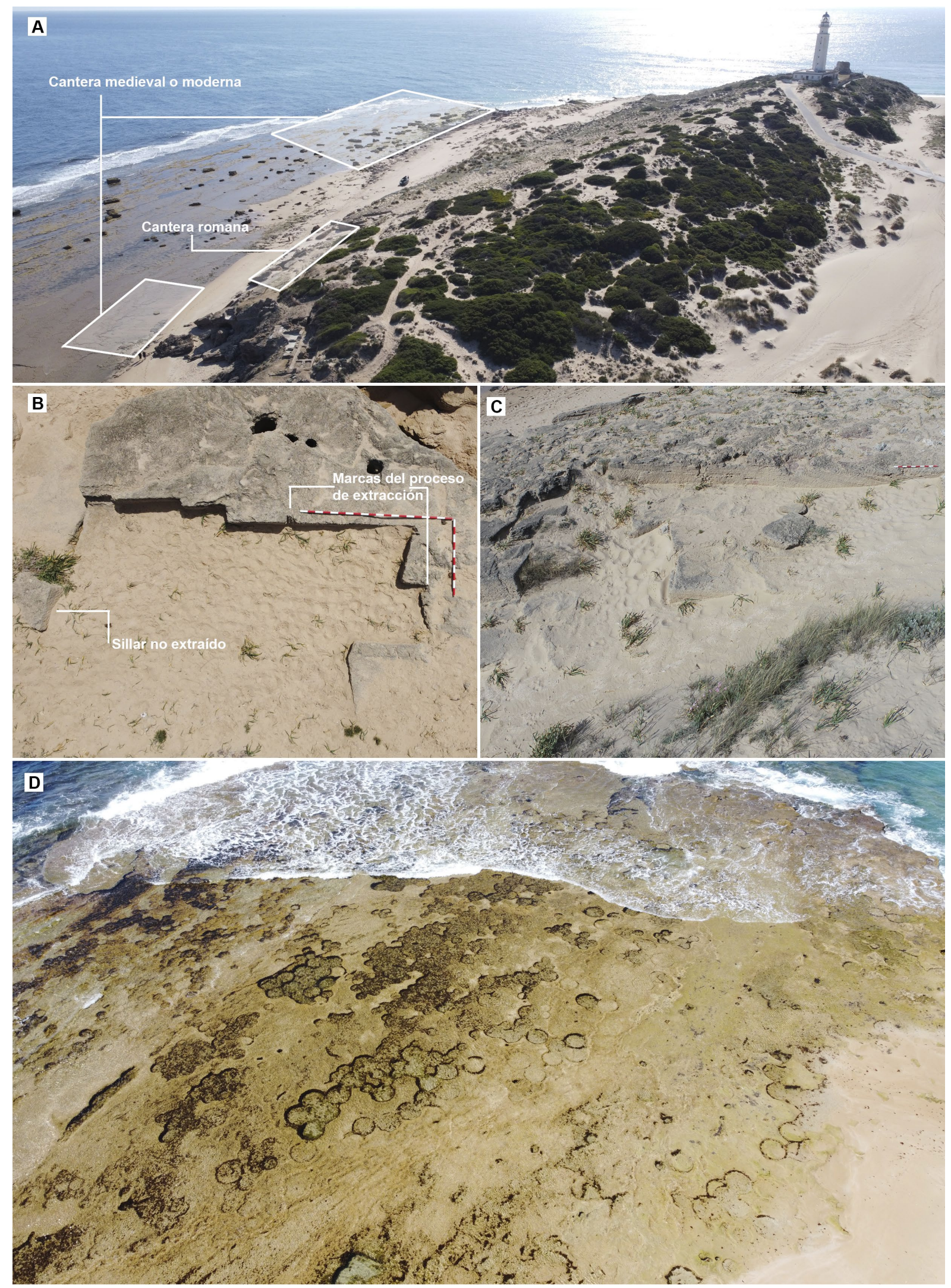

Figura 6. Vista aérea del extremo meridional del tómbolo con indicación de las dos áreas de cantería (a); detalle del área de extracción de sillares más próxima a la villa, con indicación de las principales características como zonas de retalles o sillares no extraídos (b); detalle de la segunda área de extracción de sillares de época romana (c), vista aérea de la rasa marina donde se observa el proceso de extracción de elementos líticos de módulos circulares (d). (Fuente: Proyecto Arqueostra). 
en el extremo occidental de la rasa. En esta ocasión son frentes de extracción de morfología circular (Figura 6d) con un diámetro variable de entre $1 \mathrm{y}$ $2 \mathrm{~m}$, medidas elevadas que, por tanto, abogan por desvincularlos con tambores de columnas. Además, no son excesivamente profundos -entre $30 \mathrm{y}$ $60 \mathrm{~cm}-$, por lo que la hipótesis que cobra mayor fuerza es la de asociarlo con negativos de piedras de molino. Es cierto que la biocalcarenita conchífera no es, por su naturaleza, el tipo de piedra más idóneo para la molturación, pero su uso para este fin se ha documentado desde la Prehistoria hasta nuestros días. En este sentido, mencionamos los molinos romanos documentados en el entorno de Trafalgar como puede ser el caso de los aparecidos en Baelo Claudia (Pascual, 2020) o en Iulia Traducta (Bernal-Casasola y Sáez: 2018). Sin embargo, tanto su tipología -molinos rotatorios- como su considerablemente menor tamaño nos impide hacer paralelismos entre unos y otros. Además, por el momento no existen evidencias arqueológicas en Trafalgar de instalaciones fabriles asociadas con la molienda de época romana por lo que pensamos que estos frentes de extracción situados en la rasa marina deben ser de época posterior, quizás medieval o moderna. En este caso, son innumerables los ejemplos del empleo de muelas circulares de notable tamaño en la costa gaditana, fundamentalmente en los molinos de marea de la bahía de Cádiz durante época moderna (Molina, 2001), donde las piedras soleras y volanderas son talladas en muchas ocasiones en este tipo de materia prima lítica. Queda para el futuro una revisión exhaustiva de los molinos que jalonaron la comarca de La Janda en época medieval y moderna con el fin de comparar sus piedras de molienda con los negativos de la cantera del tómbolo de Trafalgar. Aunque las principales canteras de la zona que surtieron de piedras para moler fueron las de El Berrueco y Pila de Casares en el actual T.M. de Medina Sidonia (Chaparro y Prieto, 2018), quizás algunos de esos ciento cuarenta molinos documentados en esta comarca pudieron haberse provisto de ejemplares procedentes de Trafalgar. Como ejemplo traemos a colación los molinos hidráulicos de la ribera de Santa Lucía (Bejines et al., 2016) donde, esparcidos por el entorno de dichas edificaciones, se conservan aún sus muelas, el molino de cubo de San Ambrosio o el de viento cercano al Palomar de la Breña, entre otros. En definitiva, instalaciones fabriles que deberán ser objeto de estudio en el futuro para intentar avanzar en esta hipótesis de trabajo, al mismo tiempo que se tendrán que acometer trabajos de investigación en los archivos - como el de la Casa de los Duque de Medina Sidonia- en búsqueda de información sobre los posibles permisos, arrendamientos o demás procesos administrativos vinculados con la explotación de estos terrenos para la extracción de materiales pétreos.

\subsection{La necrópolis ¿altomedieval?}

Como ya mencionamos en el apartado sobre la historiografía del lugar, en abril de 2018, y tras unas fuertes lluvias acaecidas en la zona, se pusieron al descubierto una serie de restos óseos en el acantilado del cabo de Trafalgar junto a la torre moderna. De este hecho fue alertada la Guardia Civil, la cual en un informe firmado con fecha de doce de abril daba veracidad de los hechos y especificaba que la policía judicial de Barbate al inspeccionar los restos determinó la antigüedad de los mismos. Ante esa circunstancia se dio parte al ayuntamiento de esta localidad para que técnicos municipales valoraran el hallazgo. En un escrito enviado a la Delegación de Cultura en Cádiz y firmado con fecha de 21 de mayo, A. Aragón caracterizaba la tumba como una "caja" tallada en la roca con una morfología rectangular con lo que se supone la cabecera más ancha que los pies. Además de incorporar medidas, orientación y coordenadas (36 10' 59" N, 6 2'8” 0), resaltamos tres cuestiones importantes de este informe (Aragón, 2018). En el momento de su redacción, aunque removidos, aún se conservaban en la tumba restos óseos en su interior. Por otro lado, no menciona la existencia de ningún elemento de ajuar. Por último, abría la posibilidad de su relación con los restos romanos de la villa maritima situados en el otro extremo del tómbolo.

Entre los trabajos de campo desarrollados en esta primera fase de estudio del yacimiento de Trafalgar, se ha llevado a cabo el análisis de esa área de necrópolis situada junto a la torre medieval (Figura 7a). Los trabajos de prospección superficial del terreno han deparado el reconocimiento de hasta tres sepulturas excavadas en el terreno, si bien el grado de arrasamiento de las mismas es bastante acusado. Con la nomenclatura de Tumba 1 se ha definido la sepultura localizada en 2018 junto al lienzo occidental de la torre (Figura $7 \mathrm{~b}$ ). Orientada $300^{\circ} \mathrm{NO}$, presenta una planta pseudo-rectangular con la cabecera recortada de for- 
ma aristada, estando redondeadas las esquinas de los pies. La sepultura alcanzó unas dimensiones de $1,80 \mathrm{~m}$ de longitud, y una anchura variable de entre $50 \mathrm{~cm}$ en la cabecera y zona media y apenas 20 $\mathrm{cm}$ en el extremo inferior. En cuanto al alzado, la erosión de la roca ostionera sobre la que se realizó la fosa, ha provocado que se conserve un máximo de $33 \mathrm{~cm}$ en la cabecera y $24 \mathrm{~cm}$ en los pies. En relación a la cubrición, no se ha conservado ningún elemento de ésta, por lo que desconocemos si tendría tapa o se rellenaría con tierras; si bien la primera opción es la más probable no solo por los paralelos de tumbas rupestres sino también por la existencia de dos retalles en los laterales que bien podrían haberse generado para favorecer el correcto encaje de las lajas de piedras que se usarían como cierre. En la actualidad en su interior no queda sedimento ni hueso alguno, si bien hemos tenido acceso a dos huesos que proceden de esta tumba ${ }^{8}$. A pesar de su elevado grado de fragmentación, se deben asociar uno de ellos con una tibia o fémur y el otro con un escapular o pelvis (Figura 7c) ${ }^{9}$. El primero de estos huesos ha sido datado por radiocarbono a través de la extracción de colágeno, ofreciendo una cronología calibrada de 1230 \pm 30 BP (663-775 CAL d.C. $-1287-1175$ CAL BP $)^{10}$.

Las otras dos sepulturas se encontraban inmediatas a la anterior en el acantilado. Así, a una distancia de algo más de un metro al norte de la tumba 1, definimos la segunda de las sepulturas (Figura 7d). También estaba excavada en el geológico, con la misma morfología pseudo-rectangular y una orientación de $286^{\circ}$ O. Presenta unas dimensiones de $1,80 \mathrm{~m}$ de longitud, $50 \mathrm{~cm}$ de anchura en la cabecera y zona intermedia, estrechándose de nuevo conforme alcanzaba los pies en donde el espacio interior quedaba reducido a $32 \mathrm{~cm}$. Se encontraba muy erosionada, quedando apenas unos $10 \mathrm{~cm}$ de alzado en la zona de los pies. Por su parte, la denominada como Tumba 3 se situó a algo más de $5 \mathrm{~m}$ al sur de la llamada Tumba 1 . Tenía una orientación de 2550 0 con una morfología y dimensiones similares a las anteriores, si bien el grado de erosión era aún más acuciante pues el contorno externo de la fosa se encontraba casi perdido en su totalidad tanto en el lateral meridional -a excepción de las esquinas- como en el oriental -la zona de pies- donde apenas se conservaban $4 \mathrm{~cm}$ de alzado. A grandes rasgos, la tumba alcanzó los 1,80 m de longitud y una anchura de $62 \mathrm{~cm}$ tomados en la cabecera, no siendo posible discernir si ésta se estrechó conforme descendía hasta el otro extremo (Figura 7e).

La existencia de una zona cementerial en el tómbolo de Trafalgar de finales del s. VII d.C. o del s. VIII d.C. ha sido una sorpresa, pues por el momento no tenemos constancia de poblamiento de esa época en la zona, de ahí que incluyamos el título de este epígrafe entre interrogantes. De la alquería musulmana de Beca, se excavaron dos estancias de una de sus viviendas (Abellán, 1985-1986), apareciendo asociados gran cantidad de materiales cerámicos que fueron datados entre los ss. XI y XIII (Cavilla, 1992). Además, las primeras referencias textuales a este asentamiento se encuentran en la obra geográfica de Al-Idrīsĩ del s. XII, por lo que, por ahora, no tenemos constancia de un asentamiento medieval islámico en Caños de Meca - Trafalgar durante los primeros años de la conquista musulmana de la península Ibérica. Además, por la tipología (tumbas rupestres trapezoidales), dimensiones y orientación que tampoco coincide con la islámica y sí con la cristiana (Oeste-Este; en López-Quiroga, 2010: 44), todo hace pensar que la comunidad que se enterró en Trafalgar no serían musulmanes sino cristianos de la etapa justamente anterior a la conquista o pertenecientes a una pequeña comunidad rural bajo la órbita del poder islámico, pero aún no aculturada. En este contexto, esa población seguiría la tradición de enterrarse en necrópolis rupestres, de las cuales tenemos varios ejemplos en la zona como la de Camino de Zahara, Cortijo de la Java o Cueva de Atlanterra en el entorno de Zahara de los Atunes o las de Betis, La Sanguijuela, Silla del Papa o Punta Camarinal entre otras en la ensenada de Bolonia; todas ellas generalmente adscritas a la Antigüedad Tardía (Vargas, 2011, 2014). Además, la necrópolis rupestre de Trafalgar seguiría la pauta de uno de los modelos más repetidos en relación a su emplazamiento: el de ubicarse en lugares sacralizados -en nuestro caso el promontorio dedicado a la diosa Juno- desde tiempos remotos (López, 2006; Vargas, 2011: 150).

Por último, caracterizadas las tumbas y aportada por datación absoluta su posible cronología, para el futuro sería conveniente poder determinar si la necrópolis se extiende por los alrededores, englobando un mayor número de sepulturas como por ejemplo ocurre en el caso de Betis, con más de treinta enterramientos (Vargas, 2014). Quizás parte de ella haya desaparecido, puesto que los bajos del acantilado han sufrido constantes derrumbes, tal y como se puede apreciar en los grabados conservados de la zona, donde la torre medieval no se 

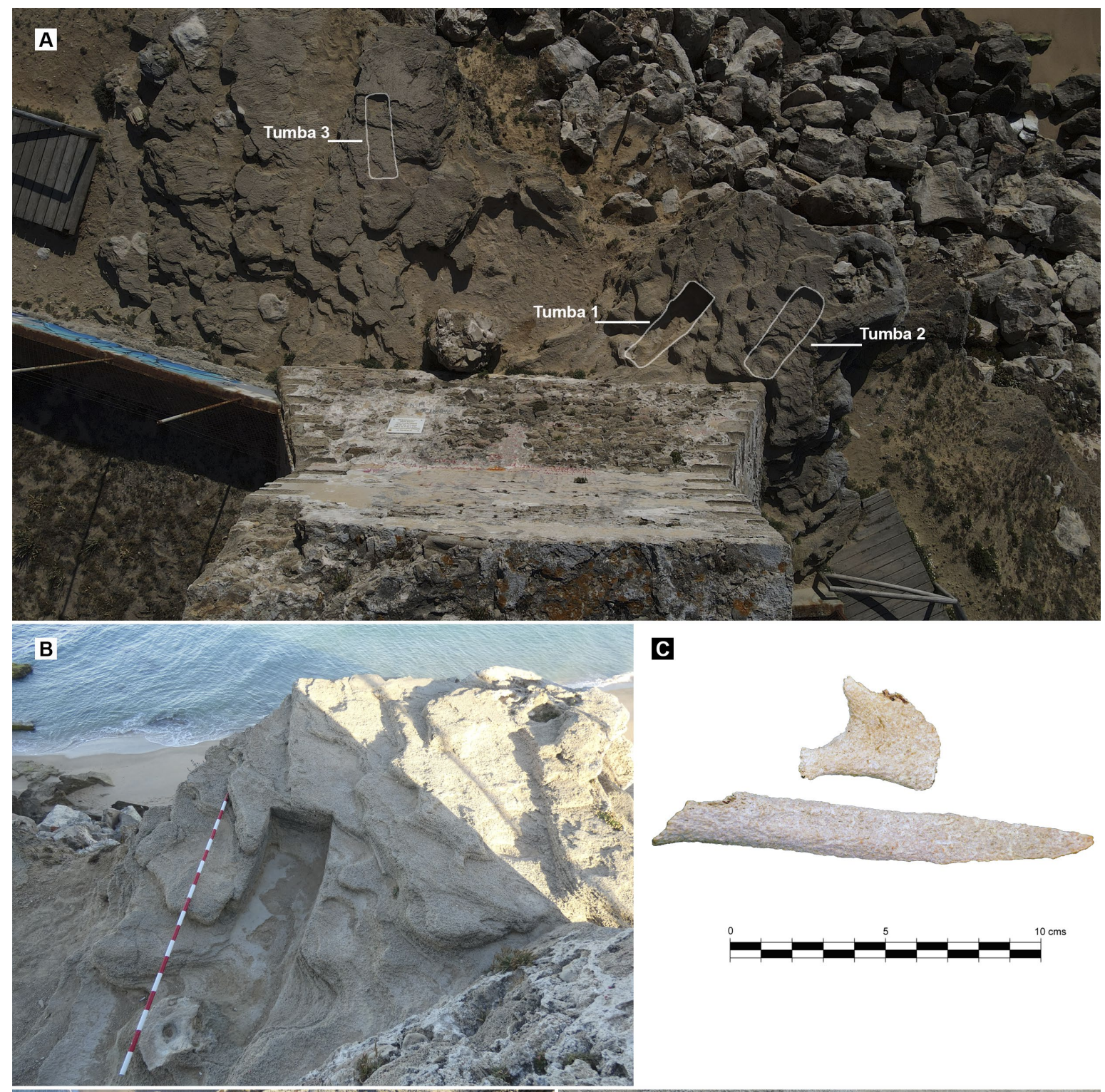

C
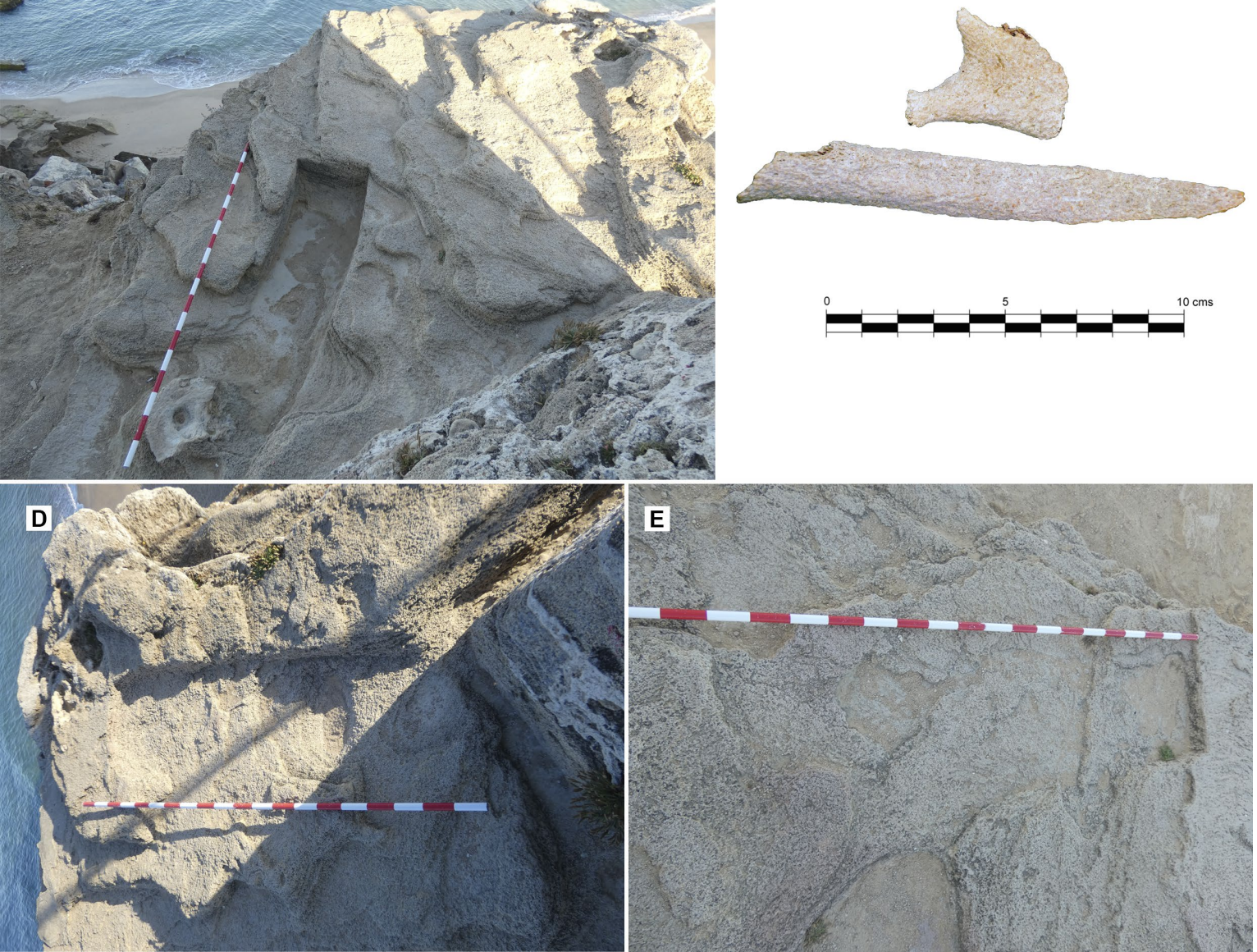

Figura 7. Vista general del acantilado del cabo de Trafalgar donde se emplazan las tumbas altomedievales documentadas (a). Detalle de la tumba excavada en la roca no 1 (b) con detalles de los fragmentos de huesos humanos recuperados del interior (c); así como detalle de los restos conservados de la tumba no 2 (d); y no 3 (e). (Fuente: Proyecto Arqueostra).

Revista Atlántica-Mediterránea de Prehistoria y Arqueología Social 23, pp. 147-170 
encuentra representada en el perfil del acantilado como ocurre actualmente. Hacia el interior, la explanada actual existente entre la torre y el faro decimonónico es un espacio diáfano y horizontal en el que bien podrían haberse emplazado otras tumbas, si bien en la actualidad el nivel de tierras superficial no permite vislumbrar este tipo de estructuras excavadas en la roca madre. En este caso, en los trabajos arqueológicos emprendidos tanto en el interior de la torre moderna como al exterior en su fachada noreste no se han encontrado evidencias de ello. Quizás los resultados de futuros trabajos de geofísica en la zona puedan en un futuro inmediato ofrecer nuevos datos y determinar la viabilidad de la hipótesis mencionada.

\subsection{La torre para la defensa de las almadrabas en época moderna}

La visión diacrónica del proyecto de investigación que estamos desarrollando en cabo de Trafalgar ha tenido su refrendo práctico en el estudio de los restos de la torre emplazada en el extremo noroccidental del promontorio, junto al cementerio altomedieval (Figura 8a). Esta torre, denominada originalmente de Meca y, posteriormente, de Trafalgar, fue una fortificación artillada para la defensa costera construida entre 1559 y 1567, por Alonso Pérez de Guzmán el Bueno, duque de Medina Sidonia, en su extenso señorío que abarcó una parte importante de la costa atlántica andaluza. Hemos de recordar que este noble llegaría a concentrar, a partir de 1588, la más alta autoridad militar en relación con la defensa del litoral y la Marina, al nombrarlo Felipe II Capitán General de la Costa de Andalucía primero, y del Mar Océano, poco después (Pidal y Salvá, 1856: 376-383). Aunque no sabemos la fecha exacta de su construcción, el mismo duque reconoció haberla promovido en un documento redactado para ilustrar su personal aportación al patrimonio familiar (estudiado por Cruz, 2005: 177). Por tanto, sabemos que tuvo que construirse después de su acceso a la jefatura de la casa, con tan solo diez años, en 1559. Luis Bravo de Lagunas, el experto enviado más tarde por Felipe II para programar la fortificación del litoral atlántico, lo ratifica al escribir en su informe de 1577 que "ha muy poco" que este duque la había levantado (Sancho de Sopranis, 1957: 62). Deducimos, a su vez, que es anterior a 1567 porque aparece correctamente situada en el cabo de Trafalgar e identificada como "torre de Meca", en el dibujo de Za- hara de los Atunes de Van den Wyngaerde (Kagan, 1986), como ya adelantó Ángel Sáez (2001: 182).

El citado informe de Bravo de Lagunas explicita su cometido al señalar que la torre fue construida para la defensa de los enemigos de los Medina Sidonia, es decir; como protección de las almadrabas de la principal amenaza del momento, el desembarco de corsarios turcos y berberiscos, en un territorio especialmente indefenso debido a la ausencia de atalayas de época islámica en la costa atlántica andaluza que pudieran ser reaprovechadas (Mora, 1981: 20). Además, el comisionado real también comprobó personalmente cómo la torre funcionaba perfectamente para la transmisión de señales (almenara), por lo que podía aprovecharse como atalaya para las almadrabas y para la comunicación con las demás torres de marina. Otra función a la que hace alusión, que había pasado desapercibida hasta ahora para la investigación, es su uso como referencia para la navegación en un punto donde debían producirse numerosos naufragios ya "que después que se hizo (...) ha librado muchos navíos, así de pescadores como de mercadería" (Sancho de Sopranis, 1957: 62).

Durante el gobierno de Pérez de Guzmán y en su minoría de edad tutelada acertadamente por su madre (Salas, 2008: 226) se edificaron en sus estados torres con diferentes modelos constructivos. El empleado en Meca se circunscribe a la fortificación de las almadrabas gaditanas y puede observarse en las dos torres septentrionales del castillo de Zahara, también anteriores a 1567, y en la torre del cabo de Roche, erigida en 1576; todas ellas realizadas con fábrica de mampostería con encadenado de sillares en las esquinas ${ }^{11}$ y planta cuadrada protegida en su base por un alambor. Este último elemento defensivo que fue introducido en la península Ibérica en el siglo XII (Barroca, 1997: 195), no se generalizará hasta mediados del siglo XV, en el marco de las innovaciones desarrolladas frente a la artillería (Mora, 1996: 35). Pese a ello, la torre de Trafalgar (Figura $8 \mathrm{~b}$ ) no sigue el modelo predominante en las torres de marina de la costa atlántica, mayoritariamente de planta circular (Sáez, 2001: 127), puesto que éstas se realizaron siguiendo las instrucciones establecidas desde 1577 por los ingenieros al servicio de la corona que, generalmente, optaron aquí por ese segundo modelo (Cámara, 1990; Mora, 1981). El tipo tampoco se corresponde con el ensayado por el mismo duque en la vecina almadraba de Castilnovo, cuya torre sigue una geometría troncopi- 


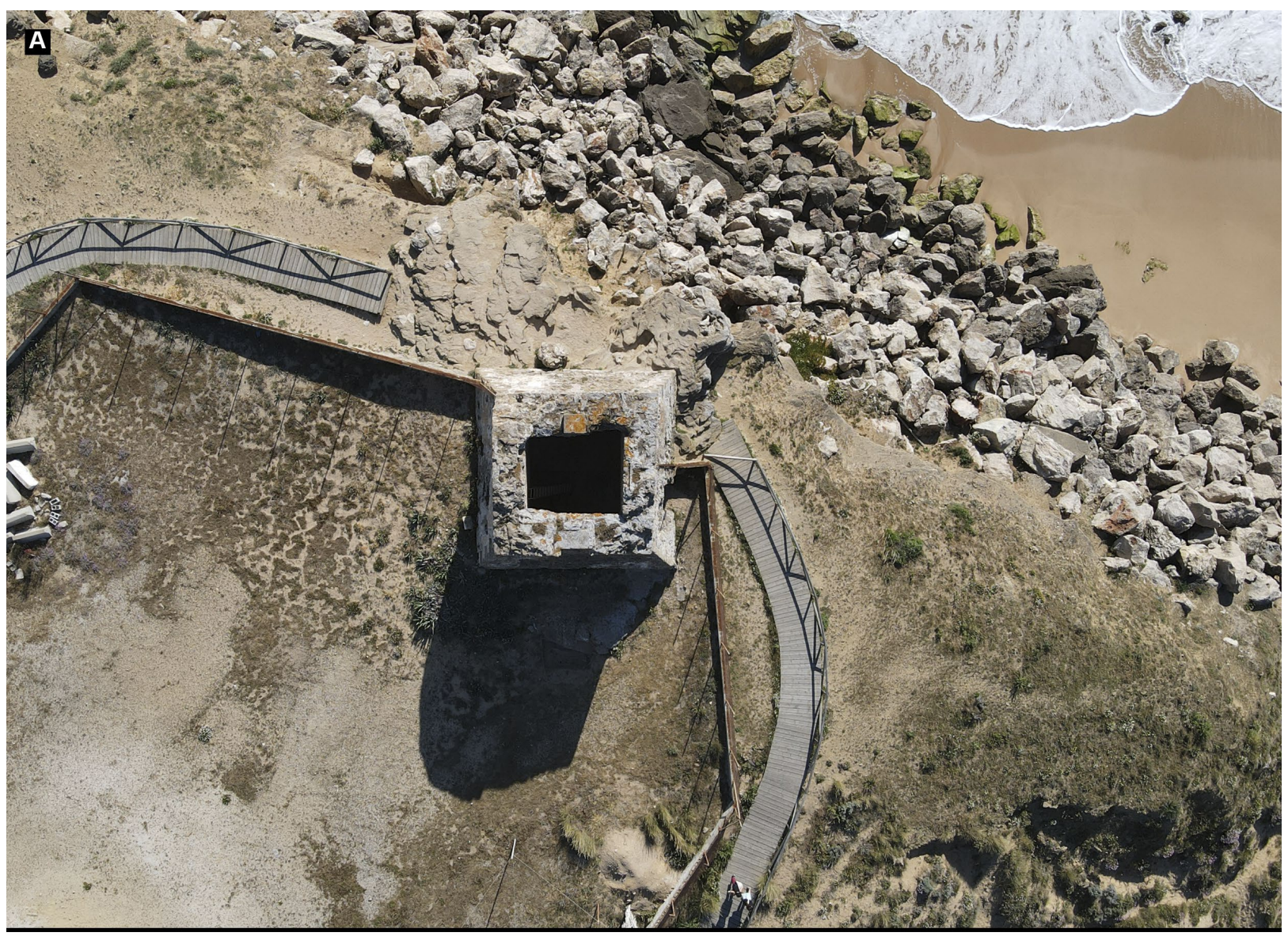

B

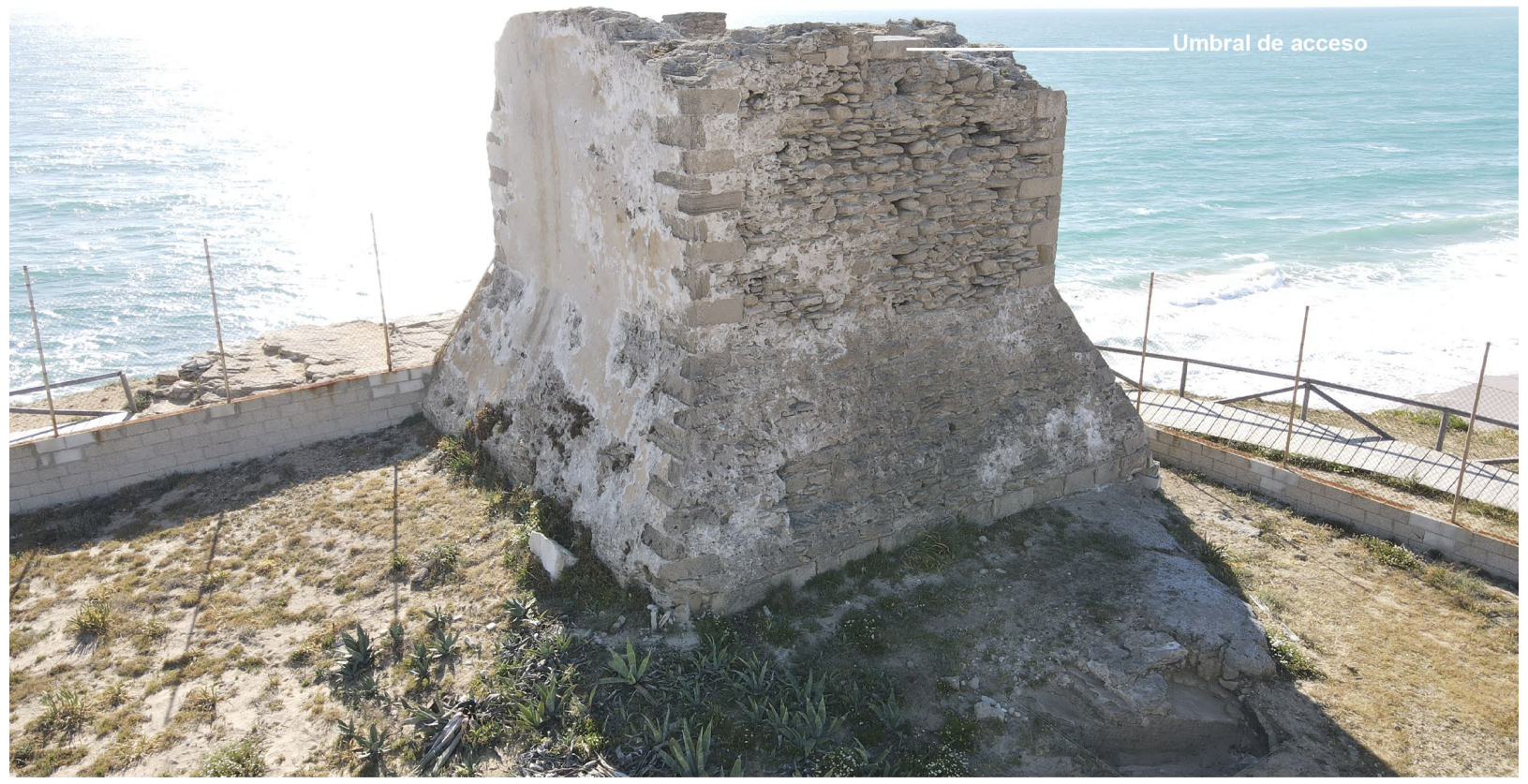

Figura 8. Vista cenital del extremo noroccidental del promontorio con la ubicación de los restos de la torre medieval (a); detalle del paramento noreste con indicación del umbral de acceso (b). (Fuente: Proyecto Arqueostra).

Revista Atlántica-Mediterránea de Prehistoria y Arqueología Social 23, pp. 147-170 
ramidal que recuerda a la empleada en las torres de Hércules, según la ilustración de la almadraba de Cádiz, realizada por Höefnagel para el Civitates Orbis Terrarum (1572). En ambos casos, se trata de atalayas vinculadas a la pesca con almadraba y dispuestas directamente en la playa, lo que explica que fueran necesariamente más esbeltas que las colocadas sobre los cabos y acantilados. No obstante, entre ellas existen algunas similitudes, pues Castilnovo emplea el mismo aparejo que Meca y Roche (mampostería con encadenado de sillares en las esquinas).

$\mathrm{Al}$ igual que esta última torre, Meca debió tener dos plantas sustentadas por bóvedas, lo que sabemos gracias a un informe de 1815 (Sáez, 2001: 184). Ambas torres utilizaron la bóveda de cañón en la planta baja y aunque, en nuestro caso, no se conserva la planta superior, es posible suponer que, como la de Roche, se cubriría con una bóveda vaída, tipología empleada también en la sala de la torre de poniente de Zahara. Menos habitual en este tipo de torres es el hecho de no presentar la planta baja macizada como es el caso que nos ocupa. Por último, en cuanto al acceso, aún se observa una parte del umbral que corrobora que éste se realizó en altura y a través de la cara opuesta al mar, como es habitual en las almenaras (Valdecantos, 1996: 495), tal y como se representa en un dibujo supuestamente de 1830 (Romero, 1994: 35). Por tanto, el butrón abierto en el alambor es claramente posterior y no coetáneo al momento de uso de la torre, puesto que para acceder a la planta baja se tuvo que perforar, no solo la base ataluzada, sino también la roca natural.

La torre siguió en pie hasta 1860 cuando fue parcialmente desmontada para la construcción del faro, una vez que había perdido toda funcionalidad. Pese a ello, debió ser testigo de uno de los episodios históricos que más trascendencia ha tenido para la historia militar contemporánea en la zona; la batalla que el 21 de octubre de 1805 enfrentó a la combinada franco-española capitaneada por Villeneuve contra la escuadra inglesa de Nelson. De la batalla de Trafalgar se han vertido ríos de tinta, teniendo en el registro arqueológico datos del hundimiento de distintos barcos a lo largo de la costa gaditana y onubense tras el temporal que se desató los días posteriores al cruento episodio bélico, siendo el buque francés Achille el único que se hundió durante la misma en el entorno de Trafalgar, tras la explosión de su santabárbara (Gallardo y Márquez, 2005: 88).

\subsection{El faro del s. XIX}

Además de algunas posibles estructuras que pudieran existir en la zona central del promontorio, con acumulaciones de sillarejos pétreos y materiales constructivo contemporáneo semienterrados por las dunas, de la fase más reciente el elemento patrimonial más interesante en cabo de Trafalgar es su faro. En este caso, hay que anotar que fue a mediados del s. XIX cuando comenzaron los estudios para proyectar la instalación de un faro en el cabo de Trafalgar. La información sobre su construcción y reforma está recogida, entre otras, en las publicaciones de T. Falcón $(1989,2005)$, donde se detalla que el proyecto primigenio fue obra de E. Saavedra y se puso en funcionamiento en el verano de 1862. La estructura, de $34 \mathrm{~m}$ de altura total y dividida en dos cuerpos, contaba además con un edificio anexo para el servicio con distintas habitaciones distribuidas en torno a un patio central (Figura 9a). El faro fue construido con sillares, muchos de los cuales fueron reutilizados de la torre medieval, por lo que, con el paso del tiempo y el cambio de maquinaria del sistema de iluminación con el consiguiente aumento de peso del cuerpo cilíndrico superior, se hizo necesario entre 1927 y 1929 reforzar la estructura. En un primer momento se pensó en hormigonar el paramento aumentando el grosor perimetral externo en medio metro. Sin embargo, el alto coste que conllevaba levantar el encofrado, obligó al encargado del proyecto de reforma J. Mururúa a apostar por tabiquería de ladrillo. Pero, por problemas en su ejecución finalmente se decidió, tras reformar el proyecto C. Iturrate, construir un total de ocho nervios perimetrales adosados a la fábrica original que se unían entre sí en la parte superior del primer cuerpo a $29 \mathrm{~m}$ de altura mediante arcos apuntados (Figura 9b). Las reformas continuaron de forma paulatina durante los años y décadas siguientes, si bien estas se han ido correspondiendo a la actualización de los sistemas de iluminación aptos tanto para la navegación marítima como aérea, quedando finalmente electrificado en la década de los setenta. Por último, indicar que actualmente sigue funcionando como vigía de la navegación e icono junto al promontorio del paisaje cultural marítimo del entorno, estando su gestión actualmente en manos de la Autoridad portuaria de la bahía de Cádiz ${ }^{12}$. 


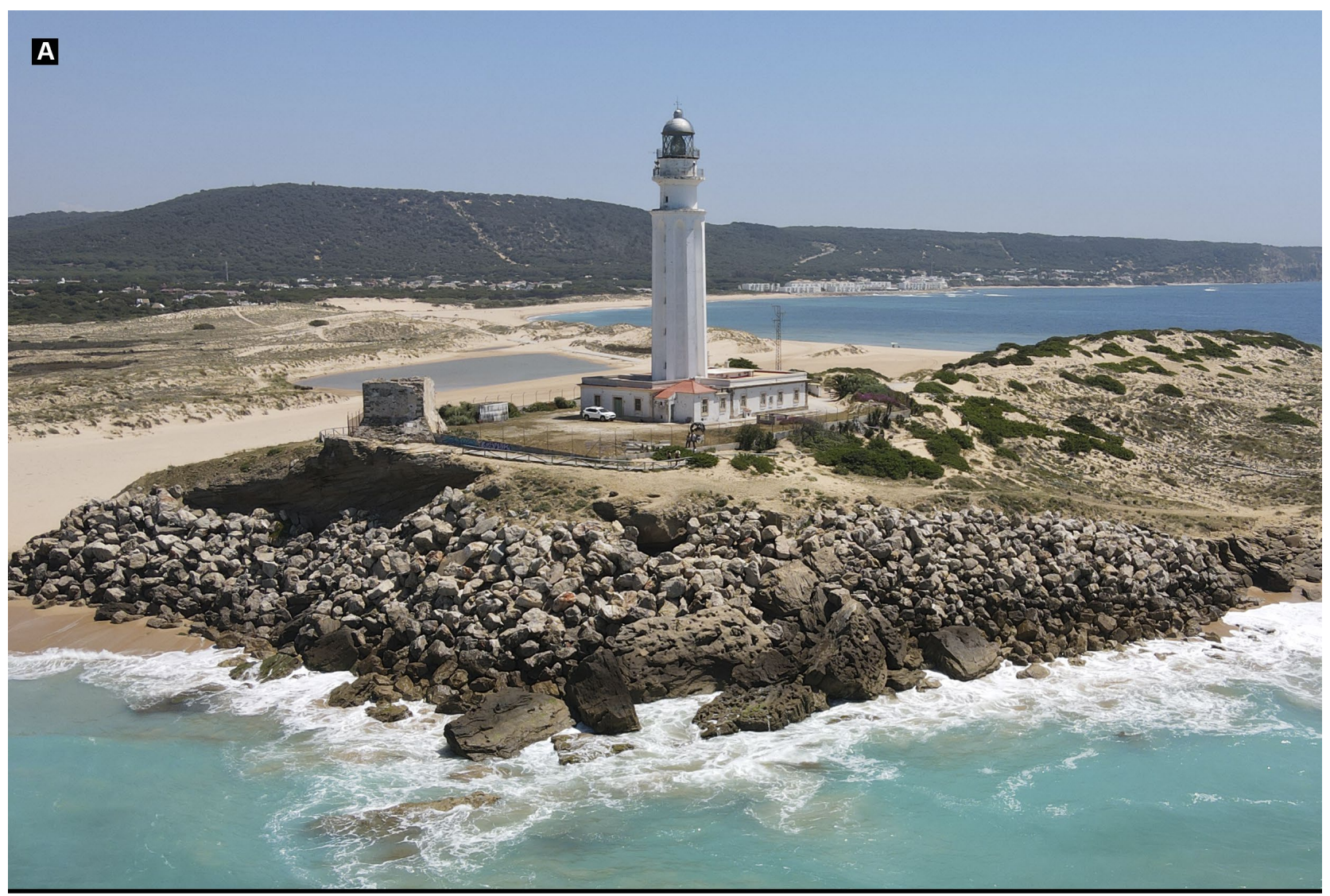

B
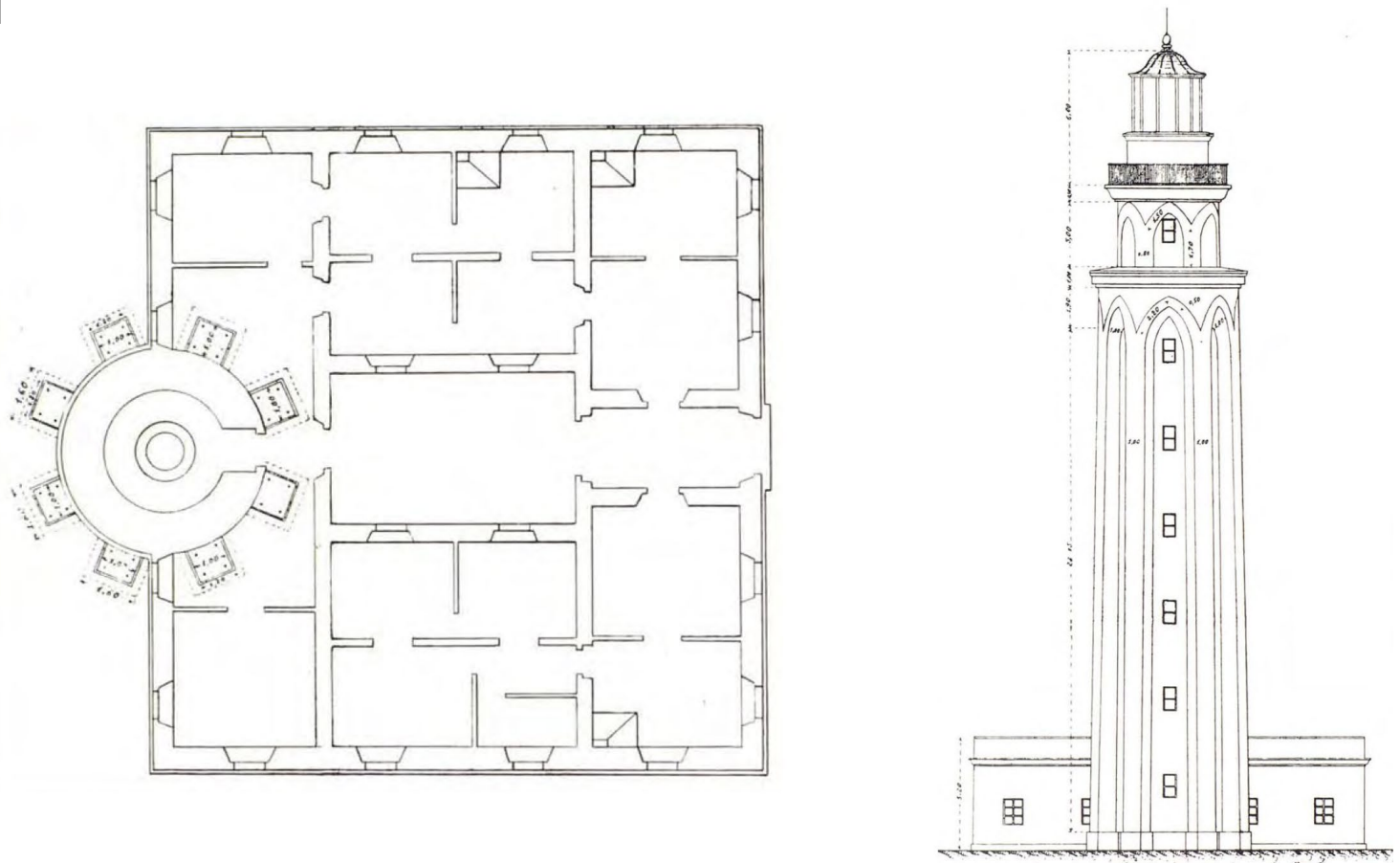

Figura 9. Vista aérea del actual faro de Trafalgar con el edificio anexo (a); planta y sección de la reforma proyectada en el faro entre 1927 y 1929 (b). (Fuente: Proyecto Arqueostra y C. Iturrate recogido en Falcón, 1989: 76-77).

Revista Atlántica-Mediterránea de Prehistoria y Arqueología Social 23, pp. 147-170 


\section{Arqueostra y el cabo de Trafalgar: perspec- tivas de futuro}

Como hemos podido observar a lo largo de estas páginas, la potencialidad arqueológica y patrimonial del cabo de Trafalgar queda fuera de toda duda, siendo uno de los espacios naturales de la costa gaditana donde el ser humano ha estado interactuando desde la Prehistoria hasta nuestros días. Los trabajos desarrollados en la zona al socaire del proyecto Arqueostra han supuesto un avance exponencial en el conocimiento sobre el Patrimonio Histórico de la comarca, y en particular del T.M. de Barbate.

Los resultados de las dos campañas de excavación efectuadas hasta el momento han sobrepasado los parámetros iniciales del proyecto que tenía en el origen de la acuicultura su finalidad más inmediata. Sin embargo y, dado el interés que ha suscitado entre las distintas administraciones y la ciudadanía, se pretende continuar con la investigación en la zona en clave diacrónica con el apoyo de la Consejería de Cultura y Patrimonio Histórico de la Junta de Andalucía y su Delegación Territorial en Cádiz, con la colaboración de la Consejería de Agricultura, Ganadería, Pesca y Desarrollo Sostenible. Para ello se hace necesario poder acometer ulteriores trabajos de campo que vengan a delimitar la extensión real de los hallazgos arqueológicos de cara a su futura protección, principalmente en la zona del balneum y posible fábrica salazonera en Caños de Meca - Varadero. El excelente grado de conservación de los restos del edificio termal redescubierto en la primavera de 2021, con más de $4 \mathrm{~m}$ de alzado en algunos casos, pronostica similares condiciones para el resto de estructuras que presumiblemente deben extenderse por los alrededores en lo que debió ser una aglomeración rural de cierta entidad que se extendió por algo más de una hectárea. De igual forma, se deberá prestar atención a la zona productiva de la villa, pues la dualidad de acuicultura - fábrica de salazón en un mismo espacio la hace singular no sólo en el entorno inmediato sino en toda la Baetica, siendo por el momento el único ejemplo recogido de una realidad económica y artesanal que tuvo que ser más común en nuestro litoral, pero que hasta el momento se resiste a salir a la luz. En este caso también se hace necesaria la realización de una propuesta de delimitación de la villa maritima, no sólo para su futura protección a efectos administrativos sino también para valorar arqueológicamente los espacios que aún deben quedar ocultos bajo la arena. Muestra de ella puede ser la localización de una estructura con algunos muros semiocultos que se sitúa en la vertiente septentrional de esa zona del promontorio (vide supra Figura 1a) y en la que la presencia en superficie de tégulas y ladrillos nos hace datarla provisionalmente en época romana y, por tanto, poderla vincular con la extensión del asentamiento villático por esa otra ladera. De forma paralela, sería interesante poder actuar en la explanada del faro, pues ésta es la zona más elevada y con mayor visibilidad por lo que no sería de extrañar que, además de la extensión de la necrópolis altomedieval, en la zona debió emplazarse el posible sacellum o templo dedicado a Juno - Hera, citado por las fuentes clásicas. Por último, no quisiéramos olvidarnos de los inicios de la ocupación humana del promontorio, con la necesidad de continuar los trabajos en el área funeraria prehistórica, pues este tipo de estructuras megalíticas como la documentada no suele encontrarse aislada. Además, el excelente estado de conservación de las estructuras, restos óseos humanos y ajuares auguran prometedores resultados a los compañeros del Área de Prehistoria de la Universidad de Cádiz que han tomado las riendas de su investigación.

Finalmente, con todo ello se podrán establecer las bases de conocimiento científico propicias para comenzar a hablar de una próxima socialización y disfrute del Patrimonio mediante la elaboración de un futuro proyecto de puesta en valor de todo el conjunto de restos arqueológicos existentes. Conociendo el potencial turístico de la zona, este proyecto, a su vez y entre otras líneas de desarrollo, podría desembocar en la plasmación de una ruta patrimonial por los Caños de Meca - Cabo de Trafalgar. Esta ruta vendría a realzar el valor histórico del lugar, y sería un valor añadido al Patrimonio Natural ya protegido, puesto que actualmente dentro de los límites del Parque Natural de la Breña y Marismas del Barbate no se cuenta con ningún tipo de Patrimonio Arqueológico musealizado y visitable.

\section{Notas}

1. Con el título oficial de "Arqueología de la ostricultura romana. Técnicas interdisciplinares para la determinación de los orígenes de la acuicultura en Andalucía y Marruecos" fue aprobado en la convocatoria de Ayudas a Proyectos de I+D+i en el marco del Programa Operativo Feder Andalucía 2104-2020 (Convocatoria 2018), de la Consejería de Transfor- 
mación Económica, Industria, Conocimiento y Universidades de la Junta de Andalucía (referencia del proyecto: FEDER-UCA18-104415). De igual forma, este trabajo se enmarca dentro del marco de ejecución de los proyectos Arqueofish (P18-FR-1483) de la convocatoria de Proyectos I+D+i Plan Andaluz de Investigación, Desarrollo e Innovación (2020), GARVM III (PID2019-108948RB-I00/ AEI / 10.13039/501100011033) del Gobierno de España/Feder, ARQ-ANALITICs de la II edición de proyectos de investigación Jóvenes Investigadores CEIMAR 2019 y del proyecto ARQUEDRONE vinculado con la convocatoria de ayudas 2020 del Campus de Excelencia Internacional en Patrimonio Cultural y Natural, (PatrimoniUN-10), para la preparación de proyectos de investigación $\mathrm{I}+\mathrm{D}+\mathrm{i}$ en cooperación con el sector privado. Asimismo, desde final de 2021 cuenta con la financiación de la Consejería de Cultura y Patrimonio Histórico de la Junta de Andalucía a través de la Delegación Territorial de Fomento, Infraestructuras, Ordenación del Territorio, Cultura y Patrimonio Histórico en Cádiz. A efectos logísticos cuenta con el apoyo de la Consejería de Agricultura, Ganadería, Pesca y Desarrollo Sostenible de la Junta de Andalucía a través de su Delegación Territorial de Cádiz, y en concreto del Parque Natural La Breña y Marismas del Barbate. Y se agradece asimismo la colaboración del Puerto de la Bahía de Cádiz, de quien depende la gestión del faro de Trafalgar.

2. A pesar de que no existe documentación de esta intervención en los archivos de la Delegación Provincial de Cultura de Cádiz, informaciones orales nos han ratificado este dato y ampliado el conocimiento sobre estos restos a los que habría que añadirle una puerta y una escalera, lo que evidenciaría el notable estado de conservación de los restos. En este caso, desde estas líneas agradecemos a A. Muñoz, inspector de la A.A.P. desarrollada por nosotros en cabo de Trafalgar la transmisión de esta información.

3. Confirmada la presencia de niveles prehistóricos in situ, se contactó con los compañeros del grupo de investigación HUM-440 (profs. E. Vijande, J.J. Cantillo y J. Ramos), quiénes asumieron a partir de ese momento los trabajos de estudio arqueológico vinculado con esta fase del yacimiento, continuando tanto la excavación de la cuadrícula $\mathrm{H}$ del sondeo 3 (una descripción detallada de los antecedentes en Bernal-Casasola et al., 2022) como de la tumba megalítica, con interesantes perspectivas de investigación futuras.
4. Debido a la importancia del contexto documentado, en el momento actual de redacción de estas páginas se está redactando también otro artículo sobre los elementos arquitectónicos empleados en la villa, liderado en este caso por José L. Portillo Sotelo.

5. Desde estas líneas mostramos nuestros agradecimientos a ambas instituciones por haber favorecido y apoyado la realización de los trabajos arqueológicos en la zona.

6. No sólo a través de RRSS sino también en la prensa con noticias que han sido publicadas más allá de nuestras fronteras como ejemplifican medios estadounidenses (https://edition.cnn.com/ travel/article/roman-baths-spain-scli-intl/index. html), rusos (https://hromadske.ua/ru/posts/ na-plyazhe-v-ispanii-raskopali-bani-drevnih-rimlyan-kotorym-25-tysyachi-let-oni-ochen-horosho-sohranilis) o chinos (https://mp.pdnews.cn/

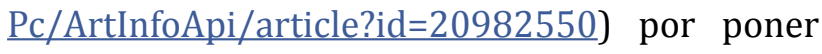
solo unos ejemplos.

7. Un estudio pormenorizado en el que se caracterizan cada una de las estancias y se da a conocer el proceso de excavación efectuado está siendo elaborado en el momento de redacción de estas páginas.

8. Tras varias visitas a la zona y observando que los restos óseos que eran visibles en la tumba iban desapareciendo, el arqueólogo Francisco Flor recogió a finales de 2018 dos fragmentos de hueso; los cuales nos fueron entregados por esta persona para su estudio, catalogación y depósito al comienzo de la puesta en marcha de los trabajos de campo en marzo de 2021. Desde estas líneas agradecemos a este arqueólogo su preocupación e interés sobre el Patrimonio Arqueológico del cabo de Trafalgar.

9. Agradecemos al antropólogo prof. Dr. Adolfo Moreno la identificación realizada.

10. Datación realizada en Beta Analitic 587215 CT/03/21 - T1.

11. Lo que puede observarse, en el caso de Zahara, en la fotografía del Catálogo Monumental (Romero de Torres, 1934) y en el de Roche, actualmente oculta por el enlucido, gracias a la descripción de Fernando Cruz (Cruz, 2014: 156).

12. No quisiéramos dejar la oportunidad de plasmar por escrito nuestro agradecimiento a la Autoridad portuaria de la bahía de Cádiz y, en concreto, a D. Antonio J. Magariño, Dña. Ana Ma Garrido y D. Esteban Naranjo por favorecer la logística del proyecto en cuanto al acceso al lugar y uso de las instalaciones. 
DÍAZ, José Juan, BERNAL-CASASOLA, Darío, FANTUZZI, Leandro, PORTILLO SOTELO, José Luis,

JIMÉNEZ-CAMINO, Rafael y EXPÓSITO, José Á.

\section{Bibliografía}

ABELLÁN PÉREZ, Juan. 1985-1986: “El despoblado de Beca". Estudios de Historia y Arqueología Medievales, V-VI. pp. 361-367.

AMORES CARREDANO, Fernando. 1978: "Una nueva factoría de salazones en Trafalgar". Habis, 9, pp. 411-453.

ARAGÓN, Antonio. 2018: Informe probable tumba en cabo Trafalgar. Original inédito depositado en la Delegación Provincial de Cultura de Cádiz, Consejería de Cultura, Junta de Andalucía.

BARROCA, Mario Jorge. 1997: "A Ordem Militar do Templo e Arquitectura Militar do século XII". Revista da Portugalia, Nova Série, vol. XVII e XVIII, pp. 171-209. Porto.

BEJINES RODRÍGUEZ, Fernando; COLLADO ÁVILA, Pablo; DAZA REBOLLO, Eva Ma; DELGADO CARRASCO, Ismael; PRIETO BAREA, Vicente. 2016: "El sistema molinar tradicional de la Ribera de Santa Lucía (Vejer de la Frontera)". Cuadernos de Transferencia, Arquitectura y Patrimonio Histórico, 3, pp. 27-34.

BERNABÉ SALGUEIRO, Antonio. 1990: Carta Arqueológica de Barbate (Cádiz). Tesis de Licenciatura (inédita). Sevilla.

BERNABÉ SALGUEIRO, Antonio. 2010: Carta Arqueológica de Barbate (Cádiz). Sevilla.

BERNAL-CASASOLA, Darío. 2016: "Promontorium Iunonis - Cabo Trafalgar (Barbate, Cádiz)". En R. HIDALGO (coord.): Las villas romanas de la Bética, vol. II, pp. 60-67. Sevilla.

BERNAL-CASASOLA; Darío; ALONSO VILLALOBOS, Carlos; GRACIA PRIETO, Fco. Javier. 2011: "De la acuicultura en Baetica. A propósito de la posible piscina-vivero del yacimiento haliéutico del cabo Trafalgar (Cádiz)". Zephyrus, LXVII, pp. 145-160.

BERNAL-CASASOLA, Darío; DÍAZ, José Juan; PORTILLO SOTELO, José Luis; FANTUZZI, Leandro; CANTILLO DUARTE, Juan Jesús; SORIGUER ESCOFET, Milagrosa. 2022: “Ostras, mejillones y la piscina loculata de la villa maritima del cabo Trafalgar (Barbate): nuevos desafíos". CUPAUAM 48, n. 1, en prensa.

BERNAL-CASASOLA, Darío; SÁEZ ROMERO, Antonio Manuel. 2018: "Molinos rotatorios en las fábricas de Traducta. Estudio arqueológico y consideraciones sobre la producción de derivados piscícolas". En D. BERNAL-CASASOLA y R. JIMÉNEZ-CAMINO (eds.): Las cetariae de Iulia Traducta. Resultados de las excavaciones arqueológicas en la calle San Nicolás de Algeciras (2001-2006), pp. 399-424. Monografías de Historia y Arte. Editorial de la Universidad de Cádiz. Cádiz.

BONSOR, George. 1918: "Les villes antiques du détroit de Gibraltar". Bulletin Hispanique, XX, pp. 141-148.

CABERO, Ana; LARIO, Javier; ZAZO, Caridad; GOY, José Luis; DABRIO, Cristino J.; BORJA, Francisco; ROQUERO, Elvira; SILVA, Pablo G.; GARCÍA-BLÁZQUEZ, Ana María; BARDAJÍ, Teresa; HILLAIRE-MARCEL, Claude; MERCIER, Norbert. 2009: "Geomorphologic setting and 1755? Tsunami deposits at Cape Trafalgar". En J. LARIO; P.G. SILVA; K. REICHERTER; C. GRÜTZNER y M.A. RODRÍGUEZ-PASCUA (eds.): Palaeoseismicity and Active Tectonics during the Quaternary in the Gibraltar Strait (Betic Cordillera, South Spain) - Field Trip 3: STOP 5, pp. 74-84. Instituto Geológico y Minero de España. Madrid.

CÁMARA MUÑOZ, Alicia. 1990: "Las torres del litoral en el reinado de Felipe II: una arquitectura para la defensa del territorio (I)". Espacio, Tiempo y Forma. Serie VII. Historia del Arte, t.3, pp. 55-68.

CAVILLA, Francisco. 1992: La cerámica hispano musulmana de Beca. Los Caños de Meca, Barbate, Cádiz. Servicio de publicaciones Universidad de Cádiz. Cádiz.

CEÁN BERMÚDEZ, Juan Agustín. 1832: Sumario de las Antigüedades romanas que hay en España, en especial las pertenecientes a las Bellas Artes. Madrid.

CHAPARRO CAMPOS, Manuel; PRIETO BAREA, Vicente. 2018: "Molinos tradicionales en la campiña de Medina-Sidonia y el territorio de frontera. Bases para la inscripción genérica colectiva en el Catálogo General del Patrimonio Histórico Andaluz". En F.J. SÁNCHEZ (coord.): II Congreso Internacional de Patrimonio Industrial y de Obra pública: Patrimonio Industrial: pasado, presente y futuro, pp. 410424. Junta de Andalucía, Fundación Patrimonio Industrial de Andalucía.

CRUZ ISIDORO, Fernando. 2005: "El mecenazgo arquitectónico de la casa ducal de Medina Sidonia entre 1559 y 1633". Laboratorio de Arte, 18, pp. 173-184.

CRUZ ISIDORO, Fernando. 2014: "La defensa de la frontera. La renovación de la arquitectura militar en el estado territorial de la Casa de 
Medina Sidonia". Laboratorio de Arte, 26, pp. 137-162.

CURTIS, Robert Irvin. 1991: Garum and salsamenta. Production and commerce in materia medica. E.J. Brill. Leiden, Nueva York, København y Colonia.

DÍAZ, José Juan; BERNAL-CASASOLA, Darío; FANTUZZI, Leandro; PORTILLO SOTELO, José Luis; FERNÁNDEZ DÍAZ, Alicia; CASTILLO ALCÁNTARA, Gonzalo. 2021: "La villa maritima del cabo Trafalgar. Avances en el conocimiento de su pars urbana". En E. FERRER (ed.): Arqueología y Numismática. Homenaje a Francisca Chaves Tristán, pp. 789-812. Editorial Universidad de Sevilla. Sevilla.

DOMÍNGUEZ-BELLA, Salvador. 2016: "Materiales rocosos en la construcción de Baelo Claudia. Análisis arqueométrico y geoarqueología de las canteras de Paloma Alta y de Punta Camarinal". Actas de las II Jornadas Internacionales de Baelo Claudia: Nuevas Investigaciones, pp. 93-105. Junta de Andalucía. Sevilla.

ETIENNE, Robert; MAYET, Françoise. 2002: Salaisons et sauces de poisons hispaniques. París.

FALCÓN MÁRQUEZ, Teodoro. 1989. Los faros de la costa atlántica andaluza. Consejería de Obras Públicas y Transportes, Junta de Andalucía.

FALCÓN MÁRQUEZ, Teodoro. 2005: "Arquitectura del mar. El universo de los faros andaluces: Costa atlántica". PH Boletín del Instituto Andaluz del Patrimonio Histórico, 53, pp. 45-54.

FORNELL MUÑOZ, Alejandro. 2005: Las villae romanas en la Andalucía mediterránea y del Estrecho. Universidad de Jaén.

GALLARDO ABÁRZUZA, Mercedes; MÁRQUEZ CARMONA, Lourdes. 2005: "Los naufragios de la Batalla de Trafalgar". PH Boletín del Instituto Andaluz del Patrimonio Histórico, 55, pp. 86-92

GRACIA PRIETO, Francisco Javier; ALONSO VILLALOBOS, Carlos; BENAVENTE, Javier; ANFUSO, Giorgio; RÍO, Laura Del. 2006: "The different coastal records of the 1755 tsunami waves along the south Atlantic Spanish Coast". Zeitschrift fur Geomorphologie N. F., 146, pp. 195220.

GRACIA PRIETO, Francisco Javier; GUTIÉRREZ MÁS, José Manuel; SÁNCHEZ BELLÓN, Ángel. 2011: "Evidencias de tsunamis, cambios ambientales y variaciones del nivel del mar en la costa atlántica de Cádiz". Geologuía del Geolodía 2011, Cádiz.
KAGAN, Richard L. (editor). 1986: Ciudades del Siglo de Oro. Las vistas españolas de Anton Van den Wyngaerde. El Viso. Madrid.

LAFON, Xavier. 2001: Villa Maritima. Recherches sur les villas litorales de l'Italie romaine. Bibliothèque des Écoles Françaises d'Athènes et de Rome, 307. Roma.

LAGÓSTENA BARRIOS, Lázaro. 2001: La producción de salsas y conservas de pescado en la Hispania romana (II a.C. - VI d.C.). Col.lecció Instrumenta 11. Barcelona.

LÓPEZ-QUIROGA, Jorge. 2010: Arqueología del mundo funerario en la Península Ibérica (siglos $V$-X). La Ergástula ediciones. Madrid.

LÓPEZ ROSENDO, Esther. 2006: "La necrópolis rupestre de la Ermita del Almendral de Puerto Serrano: un modelo de espacio funerario paleocristiano en la provincia de Cádiz". Ubi Sunt?, 20, pp. 48-61.

MARÍN CEBALLOS, María Cruz. 2010: “Imagen y culto de Astarté en la Península Ibérica. I: Las fuentes griegas y latinas". En M. L. DE LA BANDERA y E. FERRER (coords.): El Carambolo. 50 años de un tesoro, pp. 491-512. Universidad de Sevilla. Sevilla.

MARTÍNEZ SOLARES, José Manuel. 2005: "Tsunamis en el contexto de la Península Ibérica". Enseñanza de las Ciencias de la Tierra, 13-1. pp. 52-59.

MOLINA FONT, Julio. 2001: Molinos de marea de la bahía de Cádiz (siglos XVI-XIX). Consejería de Medio Ambiente, Junta de Andalucía. Sevilla.

MORA FIGUEROA, Luis De. 1981: Torres de almenara de la costa de Huelva. Diputación. Huelva.

MORA FIGUEROA, Luis De. 1996: Glosario de arquitectura defensiva medieval. Ministerio de Defensa. Cádiz.

OLCINA DOMÈNECH, Manuel. 2011: "Los viveros romanos de la Tarraconense meridional". En D. BERNAL-CASASOLA (ed.): Pescar con Arte. Fenicios y romanos en el origen de los aparejos andaluces, pp. 161-185. Monografías del Proyecto Sagena 3. Servicio de Publicaciones de la Universidad de Cádiz. Cádiz.

PASCUAL, Ma Ángeles. 2020: "Harina de pescado y otros subproductos en Baelo Claudia: acerca de la molienda en ámbito haliéutico". En D. BERNAL-CASASOLA; J.J. DÍAZ; J.A. EXPÓSITO y V. PALACIOS (eds.): Baelo Claudia y los secretos del garum, pp. 124-133. Editorial de la Universidad de Cádiz. Cádiz.

PÉREZ LÓPEZ, Inmaculada. 1989: Los santuarios 
de la Baetica en la Antigüedad: los santuarios de la costa. Tesis doctoral. Universidad de Sevilla. Edición en CD del Servicio de Publicaciones de la Universidad de Cádiz (1998).

PIDAL, Pedro José (Marqués de Pidal); SALVÁ, Miguel (editores). 1856: Colección de documentos inéditos para la Historia de España, tomo XXVIII. Imprenta de la viuda de Calero. Madrid.

PONSICH, Michel. 1988: Aceite de oliva y salazones de pescado. Factores geo-económicos de Bética y Tingitania. Madrid.

RAMOS MUÑOZ, José; CASTAÑEDA, Vicente; DOMÍNGUEZ-BELLA, Salvador; MONTAÑÉS, Manuel; ARAGÓN, Antonio; MONCAYO, Francisco; CASTAÑEDA, Antonio; VIJANDE, Eduardo; EXPÓSITO, José Ángel. 2002: "Informe de la campaña de prospecciones superficiales desarrollada en los términos de Barbate y Tarifa. Valoración en el proyecto de investigación: La ocupación prehistórica de la campiña litoral y banda atlántica de Cádiz". Anuario Arqueológico de Andalucía/1999. Tomo II, pp. 9-20. Junta de Andalucía. Sevilla.

RAMOS MUÑOZ, José; PÉREZ, Manuela; VIJANDE, Eduardo; CANTILLO, Juan Jesús. 2008. "Apéndice VIII. Yacimientos de Barbate". En J. RAMOS (Coord): La ocupación prehistórica de la campiña litoral y banda atlántica de Cádiz. Aproximación al estudio de las sociedades cazadoras-recolectoras, tribales-comunitarias y clasistas iniciales, pp. 393-425. Junta de Andalucía. Sevilla.

ROMERO, Juan Francisco. 1994: "Torres almenaras en la Ensenada de Barbate". En M. CUETO (coord.): Torres almenaras de la Ensenada de Barbate, pp. 11-43. Junta Rectora del Parque Natural Acantilado y Pinar de Barbate. Cádiz.

ROMERO DE TORRES, Enrique. 1934: Catálogo Monumental de España. Provincia de Cádiz (1908-1909). Ministerio de Instrucción Pública y Bellas Artes. Madrid.

SÁEZ RODRÍGUEZ, Ángel. 2001: Almenaras en el estrecho de Gibraltar. Las torres de la costa de la Comandancia General del Campo de Gibraltar. Instituto de Estudios Campogibraltareños. Algeciras.
SALAS ALMELA, Luis. 2008: Medina Sidonia. El poder de la aristocracia. 1580-1670. Marcial Pons. Madrid.

SANCHO DE SOPRANIS, Hipólito. 1957: "El viaje de Luis Bravo de Lagunas y su proyecto de fortificación de las costas occidentales de Andalucía de Gibraltar a Ayamonte". Archivos del Instituto de Estudios Africanos, año IX, no 42 , pp. 23-78.

SCHEFFERS, Anja; KELLETAT, Dieter. 2005: "Tsunami Relics in the Coastal Landscape West of Lisbon, Portugal". Science of Tsunami Hazards, 23 (1), pp. 3-16.

SILVA, Pablo Gabriel; GINER-ROBLES, Jorge Luis. 2014: "Terremoto ARQ004060 Bolonia (Cádiz) 40-60 a.d.". En P.G. SILVA y M.A. RODRÍGUEZ-PASCUA (eds.): Catálogo de los efectos geológicos de los terremotos en España (Serie Riesgos Geológicos/Geotécnia, 4, pp. 87-92 y 195-199. Instituto Geológico y Minero de España. Madrid,

VALDECANTOS, Rodrigo. 1996: "Las torres almenara del litoral de la provincia de Cádiz (las torres de marina): estudio tipológico y consideraciones terminológicas". Estudios de Historia y Arqueología medievales, 11, pp. 481-501.

VARGAS GIRÓN, José Manuel. 2011: “El fenómeno funerario rupestre en el campo de Gibraltar. Un estado de la cuestión". Almoraima, 42, pp. 143-165.

VARGAS GIRÓN, José Manuel. 2014: "El mundo funerario rupestre. A propósito del estudio histórico-arqueológico de la necrópolis de Betis". Al Qantir, 16, pp. 239-242.

ZAZO, Caridad; SILVA, Pablo G.; GOY, José Luis; HILLAIRE-MARCEL, Claude; GHALEB, Bassam; LARIO, Javier; BARDAJÍ, Teresa y GONZÁLEZ, Ángel. 1999: "Coastal uplift in continental collision plate boundaries: data from the Last Interglacial marine terraces on the Gibraltar Strait Area (South Spain)". Tectonophysics, 301, pp. 95-109. 